\title{
Disparate roost sites drive intraspecific physiological variation in a Malagasy bat
}

\author{
Stephanie Reher ${ }^{1}\left(\mathbb{D} \cdot\right.$ Hajatiana Rabarison ${ }^{1,2} \cdot$ B. Karina Montero ${ }^{3,4} \cdot$ James M. Turner $^{5} \cdot$ Kathrin H. Dausmann $^{1}$
}

Received: 28 June 2021 / Accepted: 21 November 2021 / Published online: 24 December 2021

(c) The Author(s) 2021

\begin{abstract}
Many species are widely distributed and individual populations can experience vastly different environmental conditions over seasonal and geographic scales. With such a broad ecological reality, datasets with limited spatial and temporal resolution may not accurately represent a species and could lead to poorly informed management decisions. Because physiological flexibility can help species tolerate environmental variation, we studied the physiological responses of two separate populations of Macronycteris commersoni, a bat widespread across Madagascar, in contrasting seasons. The populations roost under the following dissimilar conditions: either a hot, well-buffered cave or within open foliage, unprotected from the local weather. We found that flexible torpor patterns, used in response to prevailing ambient temperature and relative humidity, were central to keeping energy budgets balanced in both populations. While bats' metabolic rate during torpor and rest did not differ between roosts, adjusting torpor frequency, duration and timing helped bats maintain body condition. Interestingly, the exposed forest roost induced extensive use of torpor, which exceeded the torpor frequency of overwintering bats that stayed in the cave for months and consequently minimised daytime resting energy expenditure in the forest. Our current understanding of intraspecific physiological variation is limited and physiological traits are often considered to be fixed. The results of our study therefore highlight the need for examining species at broad environmental scales to avoid underestimating a species' full capacity for withstanding environmental variation, especially in the face of ongoing, disruptive human interference in natural habitats.
\end{abstract}

Keywords Torpor $\cdot$ Tropics $\cdot$ Physiological flexibility $\cdot$ Adaptive/facultative hyperthermia $\cdot$ Season

Communicated by Christian Voigt.

Stephanie Reher

stephanie.reher@uni-hamburg.de

1 Functional Ecology, Institute of Zoology, Universität Hamburg, Hamburg, Germany

2 Mention Zoologie et Biodiversité Animale, Faculté des Sciences, Université d'Antananarivo, Antananarivo, Madagascar

3 Biodiversity Research Institute, Campus of Mieres, Universidad de Oviedo, Mieres, Spain

4 Animal Ecology and Conservation, Institute of Zoology, Universität Hamburg, Hamburg, Germany

5 Institute of Biomedical and Environmental Health Research, School of Health and Life Sciences, University of the West of Scotland, South Lanarkshire, Scotland, UK

\section{Introduction}

Discrete populations of widely distributed species may inhabit areas with different climatic conditions and, therefore, face contrasting environmental pressures. Prevailing conditions may also vary within and among seasons, making the complete ecological sphere of a species considerably broad. Among regions, individuals may seek out similar microhabitats and consequently display relatively low potential for withstanding environmental variation, while others can adapt locally or possess highly flexible physiological traits (Kobbe et al. 2011; Noakes and McKechnie 2020; Hume et al. 2020; van Jaarsveld et al. 2021). Differences on a population level, therefore, reflect a species' capacity for phenotypic variation and/or local adaptation, and may even hint at incipient speciation (Violle et al. 2012; Richardson et al. 2014). Since physiological capacity ultimately determines species' tolerance limits to abiotic factors, and their resilience to changes in their environment (Canale 
and Henry 2010; Bozinovic et al. 2011), climatic variation can be tolerated via individuals' physiological flexibility. Brushtail possums Trichosurus vulpecula from arid habitat, for example, have a lower energy and water turnover and can dissipate heat more efficiently than conspecifics from mesic areas (Cooper et al. 2018). Similarly, big brown bat Eptesicus fuscus populations from higher latitudes have lower energetic costs at cooler ambient temperatures $\left(T_{\mathrm{a}}\right)$ during torpor than their conspecifics closer to the equator (Dunbar and Brigham 2010). As a consequence, conclusions drawn from physiological data collected during only one season and/or from a single location may under- or overestimate a species' full natural capabilities. This is especially critical in the face of ongoing human disruptive interference, when accurate research and reporting can help define suitable habitats that might serve as refugia, identify areas of increased risk and ensure the long-term viability of both populations and species (Irwin et al. 2010; Cooke et al. 2013; Rezende and Bacigalupe 2015; Cooper et al. 2018).

Bats are an ideal group for studying intraspecific physiological variation over broad environmental scales because many species are widely distributed, in some cases populating entire continents and thus a variety of habitats and environmental conditions. They are highly efficient at minimising energy expenditure and species from arid habitats can finely balance body water (e.g., Geiser and Stawski 2011; Klüg-Baerwald and Brigham 2017; Gearhart et al. 2020). Diurnal roost selection can limit exposure to unfavourable environmental conditions, such as weather extremes, help avoid predators (Fenton et al. 1994; Solick and Barclay 2006) and facilitate social interactions and reproduction (Kunz 1982; Willis and Brigham 2004). Moreover, both bat abundance and species distributions are correlated with roost availability (Humphrey 1975). Roosting sites are, therefore, a critical resource for many bats and can be an important determinant of extinction risk (Sagot and Chaverri 2015). Roosts range from well-buffered caves or crevices and tree holes, to other animals' nests, anthropogenic structures, constructed leaf tents and completely exposed roosts in foliage (Kunz and Lumsden 2003). Some species or individuals rest strictly in only one type of roost, while others change depending on seasonal and/or life history requirements (e.g., overwintering, reproduction or rearing offspring; Kunz and Lumsden 2003). Understanding the seasonal preferences of discrete bat populations for a specific roost type, and the significance of variation in these different roosts' microclimates, are therefore important steps for determining the full scope of a species' ecology and physiology.

The endemic insectivorous Commerson's leaf-nosed bat Macronycteris commersoni uses contrasting types of diurnal roost throughout its wide distribution in Madagascar (Goodman 2011). In a dry spiny forest in south-western Madagascar, M. commersoni roosts in a large colony in a hot cave with a highly stable microclimate $\left(32 \pm 0.1^{\circ} \mathrm{C}\right.$ at bat height, $98 \pm 0.5 \%$ relative humidity; Reher et al. 2018) throughout the year that is buffered from external weather (Reher et al. 2019). In a western dry deciduous forest, on the other hand, the bats roost solitarily in the open vegetation among branches (Reher and Dausmann 2021). These tree roosts provide no insulation, leaving bats vulnerable to predators and the effects of external environmental extremes. Both habitats are located in the western formations in the driest zones of the island and are highly seasonal. During the harsh dry season precipitation and food availability are reduced for up to 9 months, and night-time $T_{\mathrm{a}}$ may occasionally drop to as low as $3-6{ }^{\circ} \mathrm{C}$ (Kobbe et al. 2011; Kappeler and Fichtel 2012). During the milder wet season food resources are more abundant and night-time $T_{\mathrm{a}}$ is milder $\left(>20^{\circ} \mathrm{C}\right)$, but daytime $T_{\mathrm{a}}$ extremes regularly exceed $40{ }^{\circ} \mathrm{C}$ (Reher and Dausmann 2021). Such high $T_{\mathrm{a}}$ is challenging for the bats' thermoregulatory systems, because when $T_{\mathrm{a}}>$ body temperature $\left(T_{\mathrm{b}}\right)$ only evaporative cooling can prevent hyperthermia, which is associated with high water expenditure (Mitchell et al. 2018) and may increase the risk of dehydration in a dry region.

To conserve water and energy, both populations use torpor (Reher et al. 2018; Reher and Dausmann 2021), which is a controlled state of metabolic depression (Geiser 2004; Heldmaier et al. 2004). In general, torpor is highly beneficial. However, it is unknown how torpor patterns expressed by $M$. commersoni vary with roost type and season, and are thus modified to cope with prevailing conditions. There is evidence that torpid metabolic rate (TMR) might not vary among bat populations resting at different roosts, even though evaporative water loss could (Klüg-Baerwald and Brigham 2017; Gearhart et al. 2020; McGuire et al. 2021). However, torpor duration, frequency and general patterns, as well as resting metabolic rate (RMR), may differ at different resting sites and among seasons (Stawski and Geiser 2011; Kobbe et al. 2014; Bethge et al. 2017; Boyles et al. 2020) to support the maintenance of homeostasis.

In our study, we investigated the energetic costs and benefits of physiological strategies used by $M$. commersoni to cope with different roosting conditions, i.e. roost type and season, and quantified intraspecific physiological variation therein. We compared torpor occurrence and timing in two habitats with differing roost types: a cave with near-constant environmental conditions and an open forest with fluctuating environmental conditions. We hypothesised that bats use torpor more often, and torpor bouts are longer, in the protected cave roost, especially during the resource-poor dry season. Given that variations in TMR in thermoconforming animals are mainly a function of $T_{\mathrm{a}}$ (Geiser 2004), we predicted a higher TMR in the forest bats when torpor is used in response to heat stress (Reher and Dausmann 2021), but no differences in TMR between habitats at the same $T_{\mathrm{a}}$. We also evaluated the energetic costs associated with the 
different roosting conditions by examining body condition and daytime resting energy expenditure (DREE).

\section{Methods}

\section{Study sites}

To study the effects of roosting conditions on bat metabolism, we collected data at two sites in Madagascar separated by about $380 \mathrm{~km}$ that differ in roost availability: a cave habitat in south-western spiny forest of Tsimanampetsotse National Park and a forest habitat in western dry forest in the Kirindy Forest/Centre National de Formation, d'Etudes et de Recherche en Environnement et Forestier (CNFEREF) (Fig. 1).

Tsimanampetsotse National Park encompasses a variety of different ecosystems including dry plains around a salt lake, dry spiny forest and a calcareous plateau with underground cave and stream systems (Reher et al. 2018, 2019; Fig. 1c, e). Although it experiences a cool dry season (April to October; daily $T_{\mathrm{a}}$ fluctuations between 16.2 and $32.5^{\circ} \mathrm{C}$ ) and a hot wet season (November to March; $24.4{ }^{\circ} \mathrm{C}-38.5{ }^{\circ} \mathrm{C}$ ), this region is generally very dry yearround with only sporadic, unpredictable annual rainfall of less than $500 \mathrm{~mm}$ (or entire years without rain; Ratovonamana et al. 2013). Within the cave system, Andranolovy Cave $\left(24.04585^{\circ} \mathrm{S}, 43.75396^{\circ} \mathrm{E}\right)$ is used by $M$. commersoni and several other bat species as a diurnal roost in the wet season and for overwintering during the dry season (Reher et al. 2019; Fig. 1d). It is the hottest and most humid cave in the region and cave conditions are highly stable year-round (Table 1) (Reher et al. 2018, 2019). The bats roost at a height of $\sim 6 \mathrm{~m}$, where cave temperature is $32.4 \pm 0.1{ }^{\circ} \mathrm{C}$ and relative humidity is $98.3 \pm 0.5 \%$.

Kirindy Forest (CNFEREF) is a dry deciduous forest and is located further north $\left(20.06714^{\circ} \mathrm{S}, 44.65745^{\circ} \mathrm{E}\right.$ ) (Kappeler and Fichtel 2012; Fig. 1a, e). The climate is also characterised by a hot wet season, during which $\sim 96 \%$ of the annual rain falls $(\sim 900 \mathrm{~mm})$, and a cold dry season that can last up to nine months with little to no precipitation (Kappeler and Fichtel 2012; Goodman et al. 2018). Compared to the southern spiny forest, Kirindy Forest is denser and has a closed canopy at 15-18 m (Fig. 1a, c). Importantly,
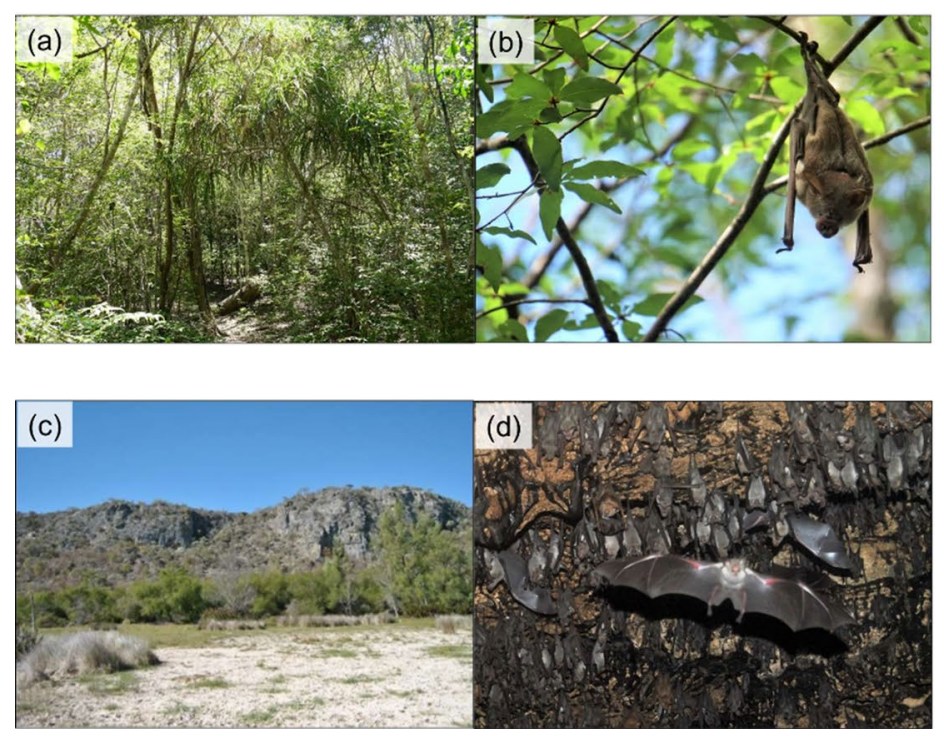
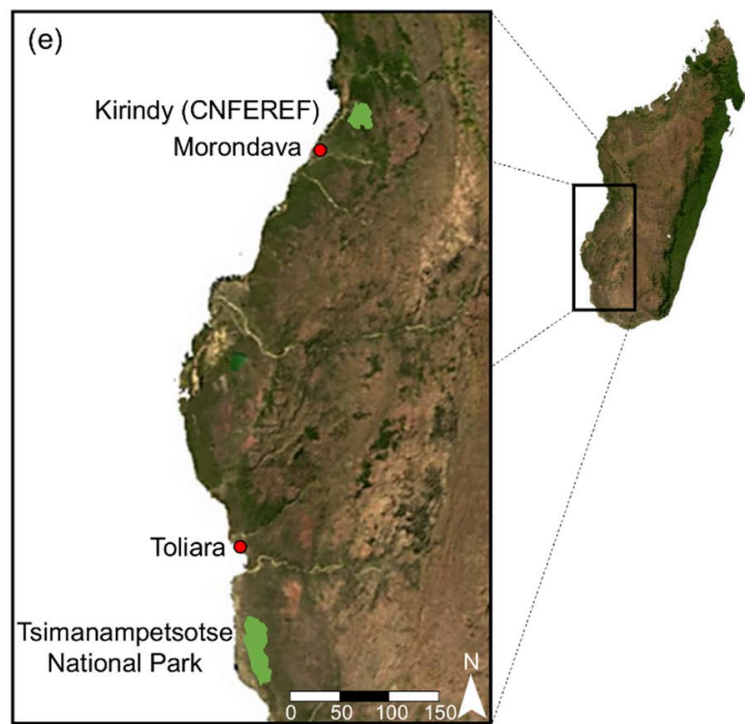

Fig. 1 Typical habitat structure and diurnal roosts of M. commersoni at the two sites studied in Madagascar (e): a foliage roost (b) in dry deciduous dry forest (a) without caves in Kirindy Forest (CNFEREF); a cave roost (d) in dry spiny forest (c) in National Park Tsimanampetsotse

Table 1 Environmental conditions (ambient temperature and relative humidity) during the wet and dry seasons at each of the sites used by $M$. commersoni, measured at a height of $1.5 \mathrm{~m}$ above the ground, in Tsimanampetsotse National Park and Kirindy Forest (CNFEREF)

\begin{tabular}{lllllc}
\hline Region & Season & Variable & Mean & Range & Daily variation \\
\hline $\begin{array}{l}\text { Tsimanampet- } \\
\text { sotse National }\end{array}$ & Dry & Cave temperature $\left({ }^{\circ} \mathrm{C}\right)$ & $29.4 \pm 0.1$ & $29.3-29.6$ & $0.1 \pm 0.1$ \\
Park & \multirow{2}{*}{ Wet } & Cave relative humidity $(\%)$ & $98.8 \pm 0.1$ & $96.4-100.5$ & $1.1 \pm 0.3$ \\
& & Cave temperature $\left({ }^{\circ} \mathrm{C}\right)$ & $30.6 \pm 0.1$ & $30.3-30.7$ & $0.2 \pm 0.1$ \\
& & Cave relative humidity $(\%)$ & $95.2 \pm 0.1$ & $93.8-96.6$ & $1.6 \pm 0.3$ \\
Kirindy Forest & \multirow{2}{*}{ Wet } & Forest temperature $\left({ }^{\circ} \mathrm{C}\right)$ & $27.5 \pm 1.2$ & $21.2-41.7$ & $13.8 \pm 2.3$ \\
$($ CNFEREF) & & Forest relative humidity $(\%)$ & $80.1 \pm 6.5$ & $29.0-101.2$ & $50.8 \pm 9.8$ \\
\hline
\end{tabular}


no caves are known to be nearby and $M$. commersoni roosts solitarily in trees, exposed to highly variable environmental conditions (Reher and Dausmann 2021; Fig. 1b). Ambient conditions fluctuate greatly on a daily basis (Table 1), with highest $T_{\mathrm{a}}$ and lowest relative humidities $\left(\mathrm{RH}_{\mathrm{a}}\right)$ occurring in the early afternoon and lowest $T_{\mathrm{a}}$ and highest $\mathrm{RH}_{\mathrm{a}}$ in the early morning. We did not trap any $M$. commersoni during the dry season, presumably because they were hibernating in tree hollows or had migrated to caves further away. Therefore, we are only able to present data from the wet season for Kirindy Forest.

To highlight the main structural differences between the two habitats that strongly affect the bats' roost characteristics, we will henceforth refer to Tsimanampetsotse National Park as the "cave roost" and to Kirindy Forest as the "forest roost".

\section{Trapping and handling}

Cave bats were trapped in June/July 2016 and February/ March 2017 (dry and wet seasons, respectively; Reher et al. 2018) and forest bats in February/March and July/August 2018 (wet and dry seasons, respectively; Reher and Dausmann 2021). We used different trapping methods owing to the differences in habitat structures and bats' roosting behaviours. During the dry season, we hand-caught adult cave-dwelling bats in the early mornings between 07:00 and 09:00 $\mathrm{h}$ because this species is generally inactive at this time of year. During the wet season we erected a two-bank $4.2 \mathrm{~m}^{2}$ harp trap (Faunatech Austbat, Bairnsdale, Australia) in front of the same cave's entrance. In the forest, two to three mist nets ( $3 \mathrm{~m}$ height $\times 6 \mathrm{~m}$ length, $19 \mathrm{~mm}$ mesh; Ecotone, Sopot, Poland) were opened each night in major flight corridors. Regardless of habitat, the harp trap and mist nets remained open for the first three hours after sunset and were checked every 10 to $20 \mathrm{~min}$, depending on season. Per trapping event, we transferred the first two adult bats into a cloth bag while additional adults and juveniles were released immediately at the capture site. Only non-reproductive individuals were studied.

All captive bats were processed at the site of capture within $30 \mathrm{~min}$. They were weighed, sex was determined and forearm length was measured. A patch of fur was removed from between the shoulder blades using a razor and shaving cream to allow the attachment of a temperaturesensitive radio transmitter ( 0.9 g, Pip Ag376; Biotrack, Wareham, UK) using a medical skin glue (Osto-Bond, Montreal, Canada or Manfred Sauer GmbH, Lobbach, Germany). The thermal sensor was placed on the skin and after attachment the transmitter itself was partially covered by the bat's fur. Transmitters weighed $\leq 2.6 \%$ of a bat's body mass $($ mean $=1.8 \pm 0.43 \%)$ and thus well below recommended maxima (e.g., Aldridge and Brigham 1988). Prior to attachment transmitters were calibrated in a water bath from $3-45{ }^{\circ} \mathrm{C}$ against a precision thermometer traceable to a national standard. Skin temperature $\left(T_{\text {skin }}\right)$ obtained via external transmitters provides a non-invasive and reliable proxy of $T_{\mathrm{b}}$, particularly in small mammals (Audet and Thomas 1996; Dausmann 2005; Langer and Fietz 2014; but see Willis and Brigham 2003). We marked all bats with an individual, three-digit wing tattoo using non-toxic ink (Hauptner-Herberholz, Solingen, Germany) after the membrane was locally anaesthetised (EMLA, AstraZeneca, Wedel, Germany). Animal handling lasted about $10 \mathrm{~min}$ and never exceeded $15 \mathrm{~min}$.

\section{Respirometry}

We measured metabolism as the rate of oxygen consumption $\left(\dot{V} \mathrm{O}_{2}\right)$ using an open-flow respirometry system in pull mode. Directly after processing, bats were transferred into individual $2 \mathrm{~L}$ plastic metabolic chambers, which were equipped with a net for roosting. Each chamber had small holes as air inlets in one wall and an outlet was connected to a portable gas analyser on the opposite side (OxBox; T. Ruf and T. Paumann, University of Veterinary Medicine Vienna, Austria), which was powered by a standard $12 \mathrm{~V}$ car battery. During measurements, sample air was drawn from the metabolic chambers at a constant flow of $50 \mathrm{~L} \mathrm{~h}^{-1}$ using a diaphragm pump, then dried with silica gel and filtered before passing through the OxBox's integrated mass flowmeter, and an aliquot thereof was drawn through the gas analyser. The oxygen content of the air was measured every $10 \mathrm{~s}$ for $55 \mathrm{~min}$. For the remaining $5 \mathrm{~min}$ per hour, reference air from outside the metabolic chambers (also dried with silica gel and filtered) was analysed for oxygen content to control for drift in the electrochemical oxygen sensors (7OX-V CiTicel; City Technology, Portsmouth, UK). This was used to correct the sample air values with the software Clampfit v10.3.1.4 (Molecular Devices, Sunnyvale, USA). The oxygen sensors were calibrated in the laboratory before and after measurements using calibration gases mixed by a gas mixing pump (19.9, 20.3 and $21.0 \% \mathrm{O}_{2}$ content; 2KM300/a, Wösthoff Messtechnik GmbH, Bochum, Germany).

The whole set-up consisting of chamber, OxBox, pump and car battery was placed within the cave or forest to measure the bats' metabolism under natural ambient conditions. Within the cave, we placed the measurement set-up in an adjoining chamber next to the bats' roosting chamber to avoid unnecessary disturbance of the whole colony. Although this chamber was slightly cooler by $\sim 3.1^{\circ} \mathrm{C}$ in the dry season and $\sim 1.1{ }^{\circ} \mathrm{C}$ in the wet season, it was frequently visited by individual $M$. commersoni. Within the forest, we placed the measurement set-up in a shaded enclosure near the camp in the centre of the forest to avoid abundant local predators such as fossas Cryptoprocta ferox. 
During each respirometry run we recorded $T_{\mathrm{a}}$ and $\mathrm{RH}_{\mathrm{a}}$ using a data logger placed within each respirometry chamber (Hygrochron iButtons, Maxim integrated, San Jose, USA) and $T_{\text {skin }}$ using a remote receiver/logger placed next to the setup (DataSika SRX-800-D; Biotrack, Wareham, United Kingdom). All temperature data were recorded at 5-min intervals.

We started measurements immediately after capture and processing, usually between 21:00 and 23:00 $\mathrm{h}$ in the wet season and 09:00 and 11:00 $\mathrm{h}$ in the dry season owing to different trapping times. We used the initial metabolic rate values after a bat was introduced to the metabolic chamber as indicators of individual stress levels. If there was no clear reduction in these first values within the next 30 or $60 \mathrm{~min}$ (depending on inactive and active phase, respectively), bats were released at their point of capture to avoid continuous stress. After the first $24 \mathrm{~h}$, all individuals were provided with fresh water $(1 \mathrm{ml})$ and food $(\sim 2 \mathrm{~g})$, but only three individuals touched the food. The three hours after feeding were omitted from analyses (see Reher et al. 2018). One respirometry run typically lasted $\sim 45 \mathrm{~h}$, thus included the activity and rest phase, and ended with the beginning of the bats' usual active phase between 17:30 and 18:30 h to ensure immediate foraging opportunities. Before the bats were released at their capture site, they were weighed and offered food and water. All applicable institutional and national guidelines for the care and use of animals were followed.

\section{Data processing and analysis}

We analysed all data using Cran R (R Core Team 2018) in "RStudio" (RStudio Team 2016) and the packages "plyr" (Wickham 2011), "dplyr" (Wickham et al. 2020), "readxl" (Wickham and Bryan 2017), "lubridate" (Grolemund and Wickham 2011), "ggplot2" (Wickham 2016), "ggpubr" (Kassambara 2020a), "cowplot" (Wilke 2020). Data are shown as mean \pm standard deviation and range if appropriate; $N$ represents the number of individuals, $n$ the number of included data points.

We first calculated the rate of oxygen consumption $(\dot{V}$ $\mathrm{O}_{2}$ ) as $\mathrm{ml} \mathrm{O}_{2} \mathrm{~h}^{-1}$ corrected to standard temperature and pressure, dry with Eq. 11.2 in Lighton (2008) before dividing by average body mass (BM) during a measurement to determine mass-specific metabolic rate (MR, $\mathrm{ml} \dot{V} \mathrm{O}_{2}$ $\left.\mathrm{g}^{-1} \mathrm{~h}^{-1}\right)$. We assumed an average respiratory quotient of 0.85 (oxidation of $50 \%$ fat and $50 \%$ carbohydrate, Dausmann et al. 2009). We determined different physiological states via visual inspection of MR patterns following Reher and Dausmann (2021). We defined torpor as a decrease in MR by at least $50 \%$ compared to resting MR (RMR), which lies within the range of the highest metabolic reductions seen during torpor in warm environments (25-84\%; Song et al. 1997; Dausmann et al. 2009; Grimpo et al. 2013; Kobbe et al. 2014). For downstream analysis, we removed arousal and entry phases and continued with a subset of MR data. We only used the lowest $50 \%$ of resting metabolic rate (RMR) values per hour per individual during the bats' usual resting phase, i.e. from sunrise to 30 min before sunset, to ensure that data from any active or disturbed animals were excluded (Bethge et al. 2017; Reher and Dausmann 2021; Rodgers and Franklin 2021). For TMR, we included the lowest $70 \%$ of data per hour per individual. We differentiated between micro-torpor bouts, the mean duration of which were as short as $17 \pm 8 \mathrm{~min}$ (range: 5-36 $\mathrm{min}, n=857$; mTMR), and extended torpor bouts lasting $4.9 \mathrm{~h} \pm 58 \mathrm{~min}$ (range: $1.7-8.3 \mathrm{~h}, n=44$; eTMR) after Reher and Dausmann (2021). Briefly, microtorpor bouts have a similar reduction in MR to extended torpor bouts but bats alternate rapidly between torpid and euthermic states without variation in $T_{\text {skin, }}$, whereas extended bouts have characteristically slower entry and arousal curves and a clear deviation in $T_{\text {skin }}$ from euthermia. We acknowledge that brief reductions in MR could also be related to a reduced respiratory rate or periods of apnoea interrupted by short breathing bursts. These are regularly observed during hibernation (e.g., Thomas et al. 1990) or shorter torpor bouts at low $T_{\mathrm{a}}$ (e.g., Morris et al. 1994), but so far not during torpor at $T_{\mathrm{a}}>25{ }^{\circ} \mathrm{C}$ (Levin et al. 2015; Geiser 2021). Furthermore, MR drops of $\sim 10 \%$ are common during sleep (Heller 1987), although the reduction might amount to $35 \%$ depending on sleep states (slow-wave sleep and rapid-eye-movement sleep) and $T_{\mathrm{a}}$ (Glotzbach and Heller 1976; Rechtschaffen 1998; Cooper and Withers 2002). However, since we observed reductions of $\sim 76 \%$ (range: $63-89 \%$ ) and at high $T_{\mathrm{a}}\left(22-36{ }^{\circ} \mathrm{C}\right.$ ), we are confident that the bats were indeed torpid.

Overall reductions in MR during torpid states were compared among roosting conditions using $t$ tests; $p$ values were adjusted with Bonferroni-Holm corrections to account for multiple comparisons (package "rstatix"; Kassambara 2020b).

$T_{\text {skin }}$ during the respirometry runs was calculated using second-order polynomial regressions obtained from the calibration curves (all $R^{2} \geq 0.99$ ) and used as a proxy for $T_{\mathrm{b}}$. Deviations in torpid $T_{\text {skin }}$ from euthermia were analysed using paired-samples $t$ tests with $p$ values adjusted with Bonferroni-Holm corrections.

\section{Bat morphology}

To compare body mass, forearm length, body condition (standardized mass index, SMI, following Peig and Green 2009, 2010) and TMR among the different roosting conditions we used $t$ tests adjusted for unequal variances if necessary or Wilcoxon signed-rank tests (package "rstatix"). 
In all cases, $p$ values were adjusted with Bonferroni-Holm corrections.

\section{Torpor bout timing and occurrence}

We used Rayleigh's tests and Watson two-tailed tests to determine whether the timing of torpor entry and arousal differed significantly from a random distribution and to identify differences in timing between sites and seasons (package "circular," Jammalamadaka and Sengupta 2001). Time is given as circular mean \pm standard deviation.

Torpor occurrence was compared between sites and seasons using two-sided Fisher's exact tests; $p$ values were adjusted with a Bonferroni-Holm correction (package "rstatix").

\section{Metabolic rates}

To analyse MR, we allocated RMR and TMR to different $T_{\mathrm{a}}$ bins by rounding $T_{\mathrm{a}}$ to the nearest integer and assigned individual means of the different metabolic states to each $T_{\mathrm{a}}$ step to avoid pseudo-replication. We then explored the influence of roost site and season (as site-season: cave dry season, cave wet season, forest wet season), sex, body condition and roost temperature on metabolic rate using either linear mixed models (LMEs) or generalized linear mixed models (GLMMs; package "Ime4", Bates et al. 2015). We did not include $\mathrm{RH}_{\mathrm{a}}$ in the models because $T_{\mathrm{a}}$ and $\mathrm{RH}_{\mathrm{a}}$ were strongly negatively correlated $\left(R^{2}=-0.78\right)$ but we report $\mathrm{RH}_{\mathrm{a}}$ mean and range during the measurements. Only $T_{\mathrm{a}}$ steps at which we measured at least three bats per roosting condition were included. We first fitted separate models for extended torpor MR (eTMR), micro-torpor MR (mTMR) and RMR, in which site-season, $T_{\mathrm{a}}$, the interaction of site-season and $T_{\mathrm{a}}$, sex and body condition were defined as fixed factors and bat ID was a random effect to account for repeated measures. Because MR is strongly associated with $T_{\mathrm{a}}$, which was almost constant in the cave but fluctuated considerably in the forest, we second modelled RMR and mTMR as a function of the roosting site at only overlapping temperature bins $\left(28-30{ }^{\circ} \mathrm{C}\right.$ and $31-34{ }^{\circ} \mathrm{C}$ ) with bat ID as random effect (the site-season variable in these models contains only two levels respectively, as the $T_{\mathrm{a}}$ in the cave did not overlap seasonally). For analysing the subset of eTMR, we used $t$ tests owing to the small sample size of bats measured at overlapping $T_{\mathrm{a}}$ steps $\left(\mathrm{N}=3\right.$ bats per site and $\left.T_{\mathrm{a}}\right)$ and non-replicated data. We excluded data from one bat that entered a single multi-day torpor bout ( $>3$ days) for the analysis of eTMR and the subsequent analysis of torpor bout duration (see below). Please note that we could not directly compare the cave-dwelling bats' MR between seasons because of no shared $T_{\mathrm{a}}$ steps (Fig. 4a-c, left panel).

Data exploration and validation was achieved following Zuur et al. (2010) and Zuur and Ieno (2016). Significance was calculated using Satterthwaite's method (package "ImerTest"; Kuznetsova et al. 2017).

\section{Torpor bout duration and frequency}

We analysed the effect of sex, body condition and siteseason on micro-torpor bout frequency, micro-torpor bout duration and extended torpor bout duration using separate GLMMs (package "glmmTMB"; Brooks et al. 2017). Microtorpor bouts occurred multiple times each day so an average bout frequency per day was used in analyses. We did not model extended torpor bout frequency because there was rarely more than one bout per day and instead report proportions of bats torpid within the populations. In all models, we included site-season, sex and body condition as fixed factors and bat ID as a random effect. For extended torpor bout duration, we defined an additional model including the interaction of site-season and body condition, and compared both using likelihood ratio testing (Zuur et al. 2009). No environmental predictor (i.e., $T_{\mathrm{a}}, \mathrm{RH}_{\mathrm{a}}$ ) was included because the site-season term encompassed per day differences in environmental variation. We ran pairwise comparisons between sites and seasons using Tukey's HSD test adjusted for multiple comparisons based on estimated marginal means or, in case the model included a significant interaction term, estimated marginal slopes (package "emmeans"; Lenth 2021).

\section{Resting energy expenditure}

To evaluate whether there were differences in bats' energetic costs among roosting conditions, we calculated individuals' daytime resting energy expenditure (DREE, in $\mathrm{kJ}$ ) between sunrise and sunset from per-minute metabolic rate values using an oxycalorific equivalent of $20.37 \mathrm{~kJ} / \mathrm{L}$ $\mathrm{O}_{2}$, derived from an assumed respiratory quotient of 0.85 (Schmidt-Nielsen 1997). This approach takes into account different daytime torpor strategies, e.g., remaining euthermic $(n=5)$, entering only micro-torpor $(n=42)$, entering only extended torpor $(6.9 \mathrm{~h} \pm 59 \mathrm{~min} N=10)$ or entering a combination of micro-torpor with a shorter extended torpor bout $(4.4 \mathrm{~h} \pm 54 \mathrm{~min} ; N=35)$. We analysed the effects of sites and seasons on DREE using a GLMM; site-season, sex, body condition and torpor strategy were included as fixed factors and bat ID as a random effect. Pairwise comparisons between sites and seasons were performed using Tukey's HSD test based on estimated marginal means (see above). 
Table 2 Overview of key physiological and morphological variables of the different populations in the dry and wet seasons

\begin{tabular}{|c|c|c|c|c|c|c|}
\hline \multirow[b]{3}{*}{ (a) } & \multicolumn{4}{|l|}{ Cave roost } & \multirow{2}{*}{\multicolumn{2}{|c|}{$\frac{\text { Forest roost }}{\text { Wet season }}$}} \\
\hline & \multicolumn{2}{|l|}{ Dry season } & \multicolumn{2}{|l|}{ Wet season } & & \\
\hline & Female (6) & Male (4) & Female (9) & Male (6) & Female (9) & Male (7) \\
\hline Body mass $(\mathrm{g})^{\circ}$ & $45.2 \pm 6.8^{\mathrm{a}}$ & $55.5 \pm 12.7^{\mathrm{a}}$ & $45.1 \pm 7.9^{\mathrm{a}}$ & $53.8 \pm 10.4^{\mathrm{a}}$ & $46.3 \pm 6.8^{\mathrm{a}}$ & $79.6 \pm 8.0^{\mathrm{a}}$ \\
\hline Forearm length $(\mathrm{mm})^{\circ}$ & $79.2 \pm 1.8^{\mathrm{a}}$ & $85.5 \pm 1.9^{\mathrm{a}}$ & $79.5 \pm 1.0^{\mathrm{a}}$ & $85.8 \pm 2.1^{\mathrm{a}}$ & $88.0 \pm 1.4^{\mathrm{b}}$ & $94.4 \pm 2.8^{\mathrm{b}}$ \\
\hline Body condition $(\mathrm{SMI})^{\circ}$ & $60.9 \pm 10.7^{\mathrm{a}}$ & $54.9 \pm 9.6^{\mathrm{a}}$ & $59.6 \pm 12.2^{\mathrm{a}}$ & $53.1 \pm 10.8^{\mathrm{a}}$ & $41.0 \pm 4.9^{\mathrm{b}}$ & $53.8 \pm 4.6^{\mathrm{a}}$ \\
\hline Bats that used extended torpor & $N=3$ & $N=3$ & $N=1$ & $N=5$ & $N=8$ & $N=7$ \\
\hline Bats that used micro-torpor & $N=5$ & $N=3$ & $N=8$ & $N=6$ & $N=9$ & $N=7$ \\
\hline (b) & \multicolumn{2}{|l|}{ Dry season } & \multicolumn{2}{|l|}{ Wet season } & \multicolumn{2}{|l|}{ Wet season } \\
\hline MR during rest $\left(\mathrm{ml} \mathrm{h}^{-1} \mathrm{~g}^{-1}\right)$ & \multicolumn{2}{|l|}{$1.04 \pm 0.19$} & \multicolumn{2}{|l|}{$1.09 \pm 0.36$} & \multicolumn{2}{|l|}{$1.05 \pm 0.42$} \\
\hline $\begin{array}{l}\text { MR during micro-torpor } \\
\quad\left(\mathrm{ml} \mathrm{h}^{-1} \mathrm{~g}^{-1}\right)(\text { reduction [\%]) }\end{array}$ & \multicolumn{2}{|c|}{$0.22 \pm 0.05\left(78.8 \pm 4.8^{a}\right)$} & \multicolumn{2}{|c|}{$0.30 \pm 0.07\left(72.9 \pm 11.8^{a}\right)$} & \multicolumn{2}{|c|}{$0.24 \pm 0.07\left(77.5 \pm 7.4^{a}\right)$} \\
\hline $\begin{array}{l}\text { MR during extended torpor } \\
\quad\left(\mathrm{ml} \mathrm{h}^{-1} \mathrm{~g}^{-1}\right)(\text { reduction }[\%])\end{array}$ & \multicolumn{2}{|c|}{$0.10 \pm 0.02\left(89.4 \pm 0.8^{a}\right)$} & \multicolumn{2}{|c|}{$0.17 \pm 0.04\left(82.4 \pm 7.1^{b}\right)$} & \multicolumn{2}{|c|}{$0.20 \pm 0.05\left(80.2 \pm 5.3^{b}\right)$} \\
\hline$T_{\text {skin }}$ during euthermia $\left({ }^{\circ} \mathrm{C}\right)^{\Delta}$ & \multicolumn{2}{|l|}{$36.4 \pm 1.7^{a}$} & \multicolumn{2}{|l|}{$36.8 \pm 1.5^{a}$} & \multicolumn{2}{|l|}{$36.6 \pm 2.0^{a}$} \\
\hline$T_{\text {skin }}$ during micro-torpor $\left({ }^{\circ} \mathrm{C}\right)^{\Delta}$ & \multicolumn{2}{|l|}{$36.1 \pm 1.4^{a}$} & \multicolumn{2}{|l|}{$35.9 \pm 1.2^{a}$} & \multicolumn{2}{|l|}{$36.1 \pm 1.9^{a}$} \\
\hline$T_{\text {skin }}$ during extended torpor $\left({ }^{\circ} \mathrm{C}\right)^{\Delta}$ & \multicolumn{2}{|l|}{$33.5 \pm 2.9^{a}$} & \multicolumn{2}{|l|}{$33.0 \pm 1.6^{a}$} & \multicolumn{2}{|l|}{$38.5 \pm 2.5^{b}$} \\
\hline Extended torpor bout duration (min) & \multicolumn{2}{|c|}{$345.2 \pm 190.4^{\mathrm{a}}$} & \multicolumn{2}{|l|}{$176.0 \pm 83.6^{\mathrm{b}}$} & \multicolumn{2}{|c|}{$312.5 \pm 157.1^{\mathrm{a}}$} \\
\hline Micro-torpor bout duration (min) & \multicolumn{2}{|l|}{$21.1 \pm 16.9^{\mathrm{a}}$} & \multicolumn{2}{|l|}{$12.8 \pm 8.9^{b}$} & \multicolumn{2}{|l|}{$13.3 \pm 6.8^{b}$} \\
\hline DREE $\left(\mathrm{kJ}^{\text {day }}{ }^{-1} \mathrm{~g}^{-1}\right)$ & \multicolumn{2}{|l|}{$0.10 \pm 0.04^{\mathrm{a}}$} & \multicolumn{2}{|l|}{$0.18 \pm 0.08^{b}$} & \multicolumn{2}{|l|}{$0.11 \pm 0.05^{\mathrm{a}}$} \\
\hline
\end{tabular}

(a) The number of females and males studied are given in parentheses. Mean body mass, forearm length and body condition; the number of bats that entered either extended or micro-torpor; mean metabolic rate during extended torpor and micro-torpor and as a percentage reduction of resting metabolism; mean torpor bout duration for both modes of torpor; and daytime resting energy expenditure (DREE) are shown. (b) We pooled sexes when calculating means of all physiological variables because sex was not included in the most parsimonious models. For simplicity, MR reduction was compared over the mean of the entire measured $T_{\mathrm{a}}$ range because testing among subset $T_{\mathrm{a}}$ ranges yielded the same trends. Different superscript letters indicate statistical differences (see "Results" for details)

${ }^{\circ}$ only within sex comparisons across roosting conditions (see supplements)

${ }^{\Delta}$ only analysed within sites and seasons, i.e. letters indicate differences observed among metabolic states under the same roosting condition

\section{Results}

We measured the physiological responses of 41 individual M. commersoni; 25 from the cave roost and 16 from the forest roost (Table 2). We studied cave bats during the wet and dry season. In the forest, however, we did not trap any bats during the dry season despite 261 trapping hours and thus only present forest data from the wet season (Table 2). Bats from the forest population were larger but not heavier than their conspecifics from the cave roost (Table 2, Table S1). Interestingly, body condition was similar in both roosting conditions and sexes, but the forest population's females had a significantly lower body condition than all other bats $(t$ test, $t_{27.7}=-6.54, p<0.001$; Table 2).

\section{Occurrence of torpor and deviations from euthermia}

Most bats (38 out of 41) entered torpor ( $n=44$ extended bouts, $n=857$ micro-torpor bouts). Only three cave-roosting individuals remained normothermic over the whole measurement period (one female in the wet season and one female and one male in the dry season). During the wet season the forest bats made extensive use of both modes of torpor (94\% used extended torpor and 100\% used microtorpor), and more bats used extended torpor compared to the cave population (Fisher's exact test, $p=0.006$ ), which opted for micro-torpor (94\%) rather than extended torpor (40\%; Fisher's exact test, $p=0.005$ ). During the dry season, a comparable proportion of bats used extended torpor (60\%; Fisher's exact test, $p=0.428)$ and micro-torpor $(80 \%$; Fisher's exact test, $p=0.968$ ). Overall mTMR was reduced by $75 \%$ compared to RMR, without differences between sites or seasons (cave dry vs. cave wet season: $t_{21.0}=1.13$, $p=0.271$; cave dry vs. forest wet season: $t_{17.9}=-1.62$, $p=0.246$; cave wet vs. forest wet season: $t_{21.8}=-2.54$, $p=0.057$; Table 2). The greatest reductions in eTMR were observed in the cave during the dry season $(89.4 \pm 0.8 \%$; cave dry vs. cave wet season: $t_{9.25}=-2.51, p=0.031$; cave dry vs. forest wet season: $t_{11.2}=-3.30, p=0.004$ ) and comparable reductions in the wet season regardless of roost 


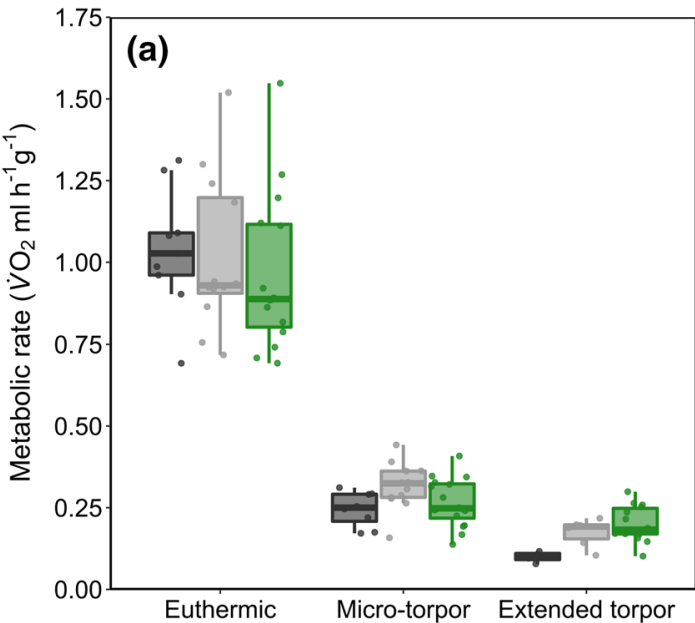

Fig. 2 a Mean mass-specific metabolic rate $\left(\dot{V} \mathrm{O}_{2}\left(\mathrm{MR}, \mathrm{ml} \mathrm{h}^{1} \mathrm{~g}^{1}\right)\right.$ and $\mathbf{b}$ skin temperature $\left(T_{\text {skin }},{ }^{\circ} \mathrm{C}\right)$ of animals at rest (euthermic), in a micro-torpor bout and in an extended torpor bout. Bats roosting in a cave during the dry (dark grey) and wet season (light grey) and forest-

type (forest: $80.2 \pm 5.3 \%$, cave: $82.4 \pm 7.1 \% ; t_{8.51}=-1.262$, $p=0.223$; Fig. 2a). Although the drop in MR during torpor was considerable, changes in $T_{\text {skin }}$ were less evident (Table 2, Fig. 2a, b): it was not possible to detect micro-torpor bouts through a clear $T_{\text {skin }}$ signal under any roosting conditions studied (cave dry season: $t_{7}=0.14, p=0.185$; cave wet season: $t_{13}=1.73, p=0.071$; forest wet season: $t_{15}=0.86$, $p=0.402)$. However, $T_{\text {skin }}$ deviation from euthermia indicated an extended torpor bout. In the cave, $T_{\text {skin }}$ dropped by $2.9 \pm 2.0^{\circ} \mathrm{C}$ during extended torpor (cave dry season: $t_{4}=3.29, p=0.047$; cave wet season: $t_{5}=4.55, p=0.014$ ) but increased by $1.9 \pm 2.8^{\circ} \mathrm{C}$ in the forest $\left(t_{13}=3.18, p=0.022\right.$; Table 2, Fig. 2b), where extended torpor was most commonly associated with higher $T_{\mathrm{a}}$ than in the cave (Reher and Dausmann 2021).

\section{Temporal synchronisation of torpor bouts}

We found seasonal and site-specific timing in entry into torpor and arousal from torpor. The entry and arousal times of both extended and micro-torpor bouts were randomly distributed in the cave during the dry season (table S2, Fig. 3a, b), when the bats did not leave the cave for months. In the wet season, extended torpor and micro-torpor entry and arousal followed a clear pattern at both sites (Table S2, Fig. 3c, d, e, f), and the timing of extended torpor entry and arousal was more synchronized than for micro-torpor (i.e., extended torpor bout times had higher Rayleigh's r-values). The bats in the cave entered into and aroused from extended torpor earlier than in the forest (entry: $x=0.24, p<0.05$, cave 09:21 $\pm 40 \mathrm{~min}$, forest 10:23 $\pm 12 \mathrm{~min}$; arousal: $x=0.1872$, $p<0.05$ cave $14: 54 \pm 29 \mathrm{~min}$, forest $16: 56 \pm 17 \mathrm{~min}$;

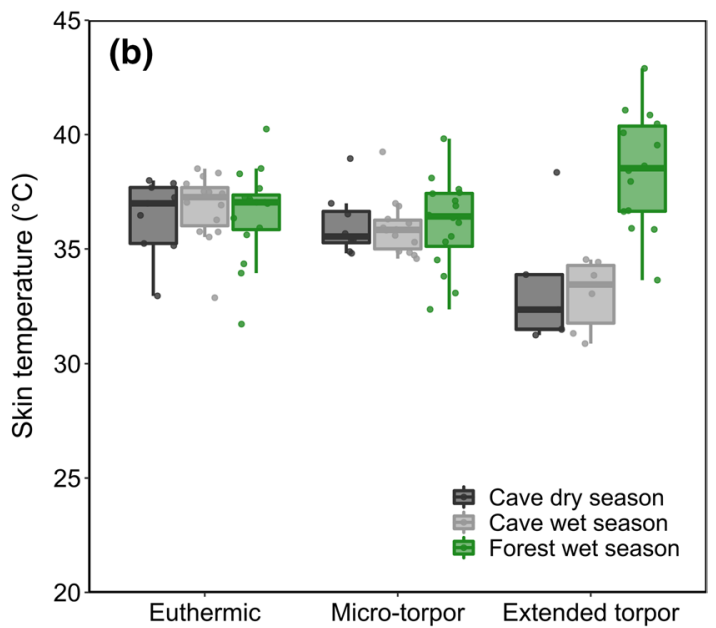

dwelling bats during wet season (green). The centre line represents the median, box limits indicate upper and lower quartiles, whiskers show $1.5 \times$ interquartile range and points are all included data

Table S2; Fig. 3c, e). Micro-torpor bouts appeared to occur around the clock in the wet season but entry and arousal times differed from a random distribution (Table S2, Fig. 3). In the cave, both were more frequent during the day (entry: 12:58 $\pm 5 \mathrm{~min}$, arousal: $13: 18 \pm 7 \mathrm{~min}$ ), whereas in the forest entries and arousals occurred predominantly in the mornings (entry: 09:28 \pm 9 min, arousal: 09:43 $\pm 11 \mathrm{~min}$; Table $\mathrm{S} 2$; Fig. 3d, f), often before extended torpor bouts at high $T_{\mathrm{a}}$.

\section{The effect of roosting environment on MR}

We analysed the RMR of 39 individuals. The interaction of site-season and $T_{\mathrm{a}}$ step $\left(C h i^{2}=8.70, p=0.013\right)$ had a significant effect on RMR. RMR generally decreased with increasing $T_{\mathrm{a}}(t=-3.30, p<0.001)$, but the slope was significantly flatter in the forest (forest wet vs. cave dry season: $z$-ratio $=2.64, p=0.023$; forest wet vs. cave dry season: $z$-ratio $=-1.97, p=0.036$; Fig. $4 \mathrm{a}$, left panel) than in the cave, where the slope did not differ between seasons $(z$-ratio $=-0.92 ; p=0.625 ;$ Fig. $4 \mathrm{a}$, left panel $)$. There was no significant variation in a subset of RMR at similar temperature ranges $\left(28-30{ }^{\circ} \mathrm{C}: t=-0.50, p=0.613, N=26\right.$; $31-34^{\circ} \mathrm{C}: t=-0.45, p=0.650, N=25$; Fig. $4 \mathrm{a}$, right panel). Higher body condition was correlated with lower RMR $(t=-2.17 ; p=0.030)$ but sex was not a significant predictor $(t=0.82 ; p=0.412)$.

Micro-torpor MR decreased slightly with increasing $T_{\mathrm{a}}(t=-4.52, p=0.034, N=38$; Fig. 4b, left panel). Neither site-season (cave wet season $t=0.92, p=0.362$; forest wet season $t=0.42, p=0.664)$, body condition $(t=-0.97$, $p=0.340)$, nor sex significantly affected $\operatorname{mTMR}(t=0.17$, $p=0.870$ ). Accordingly, site-season was not a significant 
Fig. 3 Timing of entry into (mauve), and arousal from (black), extended and micro-torpor bouts under three different roosting conditions: in a cave during the dry and wet seasons (a, b and $\mathbf{c}, \mathbf{d}$, respectively) and in a forest during the wet season $(\mathbf{e}, \mathbf{f})$. For extended torpor (a, c, e), the data show the time of the day (circular axis) and skin temperature $\left({ }^{\circ} \mathrm{C}\right.$; radial axis distance). Dark grey shaded areas indicate scotophase and light grey areas indicate twilight. The green line illustrates hourly mean ambient temperature with hourly minima and maxima bounding the green shaded areas. For micro-torpor $(\mathbf{b}, \mathbf{d}, \mathbf{f})$, the data show the occurrence of micro-bout entries (mauve) and arousals (black; radial distance) over the course of the day at hourly intervals

\section{Extended torpor}
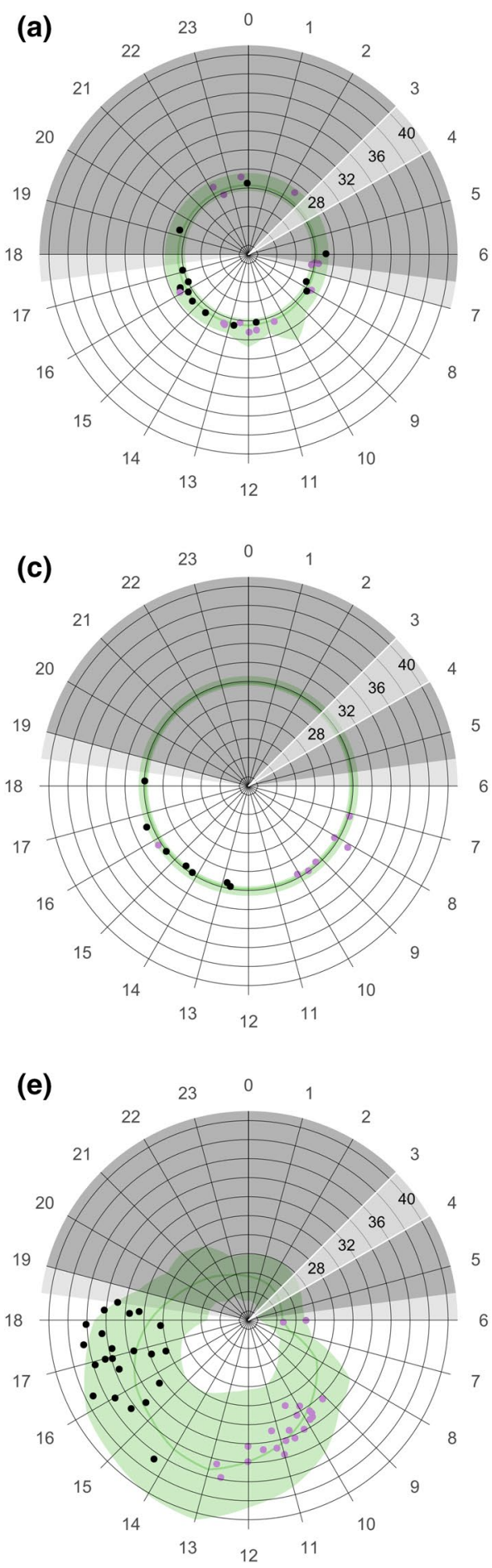

Micro-torpor
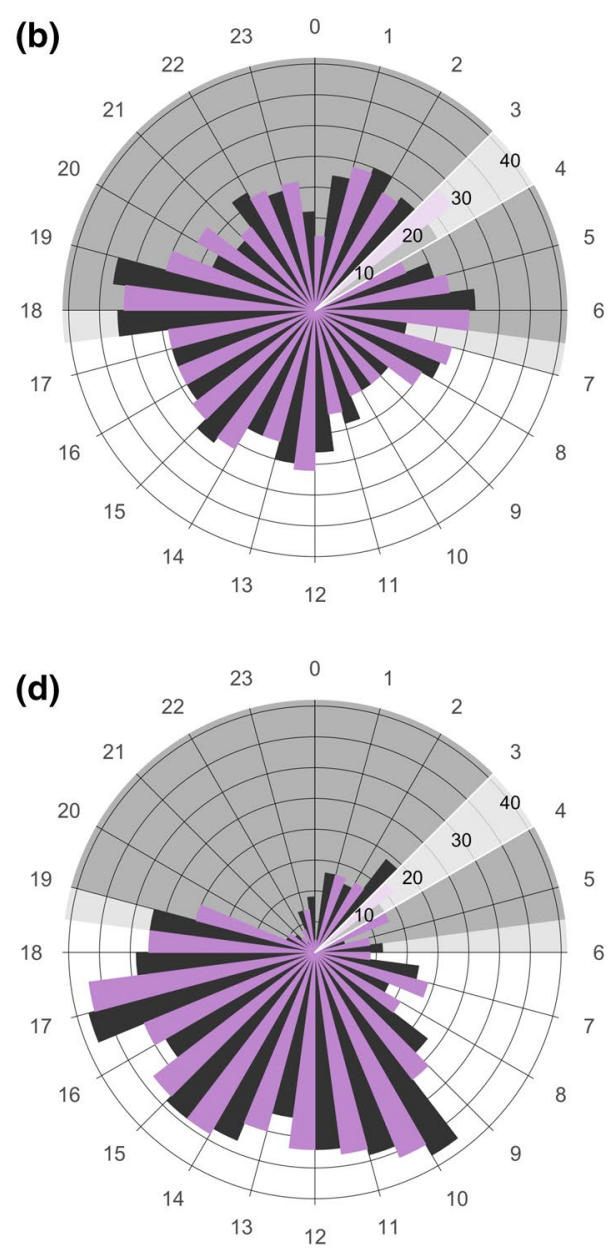

(f)

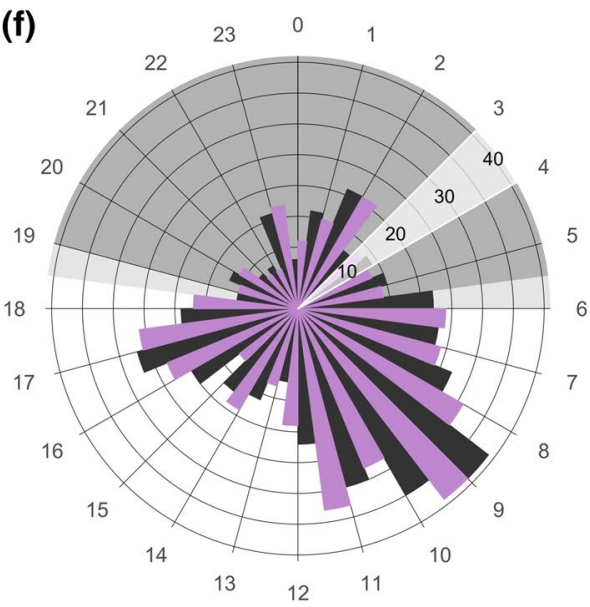

predictor of a subset of mTMR at only similar temperature ranges $\left(28-30{ }^{\circ} \mathrm{C}: t=0.807, p=0.43, N=23 ; 31-34{ }^{\circ} \mathrm{C}\right.$ : $t=-0.97, p=0.340, N=26$; Fig. $4 \mathrm{~b}$, right panel).

We analysed eTMR for 25 individuals. In the forest population, eTMR increased with increasing $T_{\mathrm{a}}(t=8.87$; $p<0.001$; Fig. 4c, left panel) while sex $(t=-0.06$; $p=0.951)$ and body condition had no significant effect $(t=0.11 ; p=0.912)$. We found no differences in a subset of eTMR at similar $T_{\mathrm{a}}\left(29^{\circ} \mathrm{C}: t_{2.48}=-0.08, p=0.946, N=6\right.$; $32{ }^{\circ} \mathrm{C}: t_{9.28}=-0.12 ; p=0.909 ; N=15$; Fig. $4 \mathrm{c}$, right panel). 

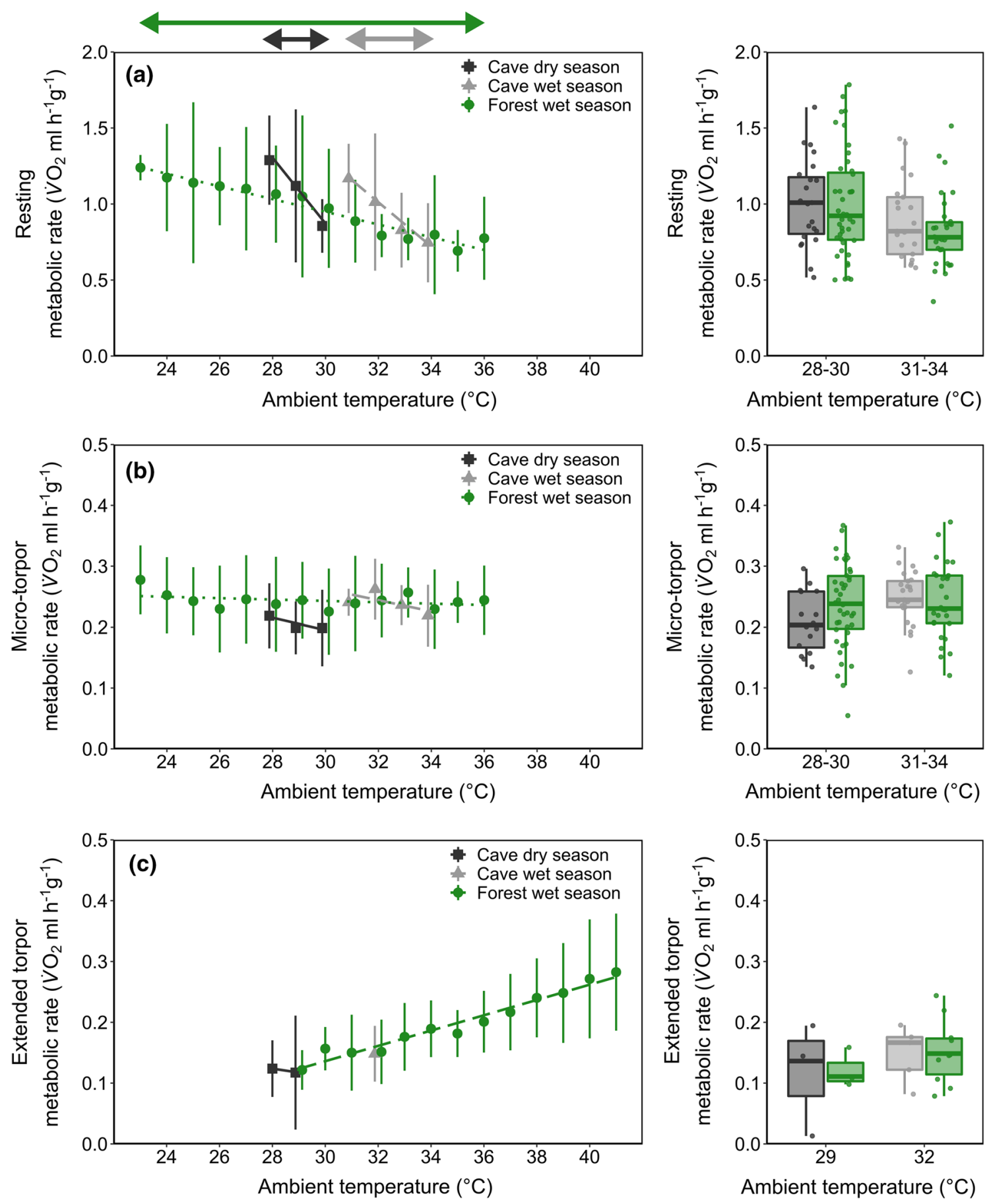

Fig. 4 The mass-specific metabolic rate (MR, ml $\dot{V} \mathrm{O}_{2} \mathrm{~h}^{-1} \mathrm{~g}^{-1}$ ) of bats when a resting, $\mathbf{b}$ in micro-torpor and $\mathbf{c}$ in extended torpor in a cave in the dry season (dark grey squares), the same cave in the wet season (light grey triangles) and a tree roost in the wet season (green circles). The left panel shows MR as a function of ambient temperature; error bars represent standard deviation. The arrows above the left panel indicate the $T_{\mathrm{a}}$ range and colours correspond with roost/season. The right panel shows MR at only overlapping ambient temperature (centre line, median; box limits, upper and lower quartiles; whiskers, $1.5 \times$ interquartile range; dots, data included). Please note the different $y$-axis scale of $\mathbf{b}$ and $\mathbf{c}$ 


\section{Torpor bout frequency and duration}

Site-season affected micro-torpor bout frequency $\left(C h i^{2}=15.12, p<0.001, N=37, n=76\right)$. The cave-dwelling bats in the wet season entered micro-torpor bouts more frequently than their conspecifics (cave wet vs. cave dry season: $z$-ratio $=-3.67, p<0.001$; cave wet vs. forest wet season: $z$-ratio $=-2.51, p=0.033$ ), while the frequency of micro-torpor bouts per day was similar for cave bats in the dry season and forest-dwelling bats in the wet season $(z$-ratio $=-1.33, p=0.376$; Fig. 5a). Micro-torpor bout frequency was influenced by sex, with females entering microtorpor more frequently than males $(z=-2.27, p=0.023)$; body condition had no effect on the frequency of microtorpor bouts $(z=1.77, p=0.077)$. For micro-torpor bout duration, site-season was the single significant predictor $\left(C h i^{2}=22.37, p<0.001, \mathrm{~N}=37, n=76\right)$. Cave-dwelling bats entered longer bouts in the dry season than bats in the
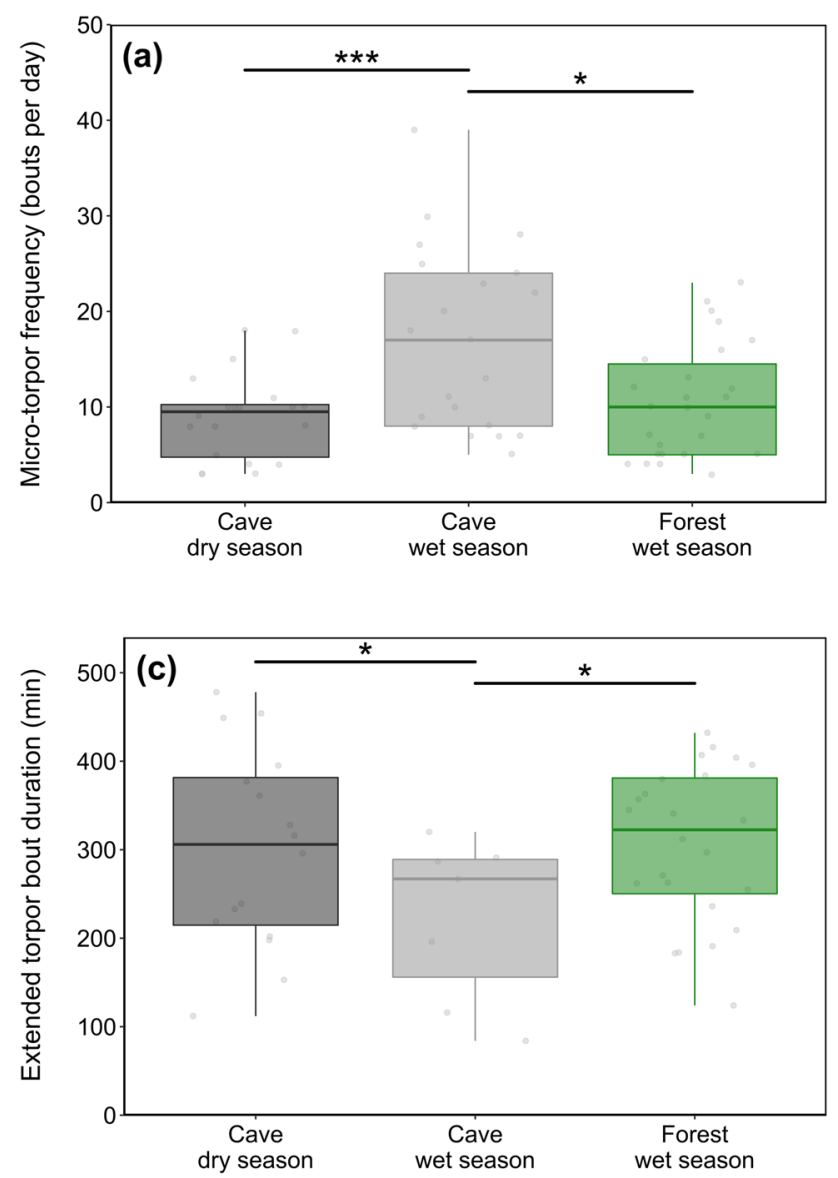

Fig. 5 a Micro-torpor bout frequency, b micro-torpor bout duration and $\mathbf{c}$ extended torpor bout duration of individuals roosting in the cave in the dry season (dark grey) or wet season (light grey) and in the forest in the wet season (green). $\mathbf{d}$ shows daytime resting energy expenditure according to metabolic strategy (remaining euthermic, red; entering micro-torpor bouts, orange; entering micro-torpor bouts wet season, regardless of roost type (cave dry vs. cave wet season: $z$-ratio $=4.18, p<0.001$; cave dry vs. forest wet season: $z$-ratio $=4.27, p<0.001$; cave wet vs. forest wet season: $z$-ratio $=0.26, p=0.962$; Fig. $5 b)$. Neither sex $(z=0.16$, $p=0.875)$ nor body condition $(z=-0.50, p=0.617)$ influenced micro-torpor bout duration significantly.

Extended torpor bout duration was better explained when the interaction of site-season and body condition was included $\left(C h i^{2}=3.97, p=0.036\right)$. In cave conditions, extended torpor bout duration was negatively related to body condition but the slope of this relationship was steepest during the dry season than during the wet season ( $t$-ratio $=-2.06, p=0.013, N=24, n=48$; figure S1). The duration of extended torpor bouts was shortest in wet season cave bats (cave wet vs. cave dry season: $t$-ratio $=2.93$, $p=0.024$; cave wet vs. forest wet season $t$-ratio $=2.34$, $p=0.048)$ and similar between wet season forest bats and dry season cave bats $(t$-ratio $=-0.86, p=0.655$; Fig. 5 c) .
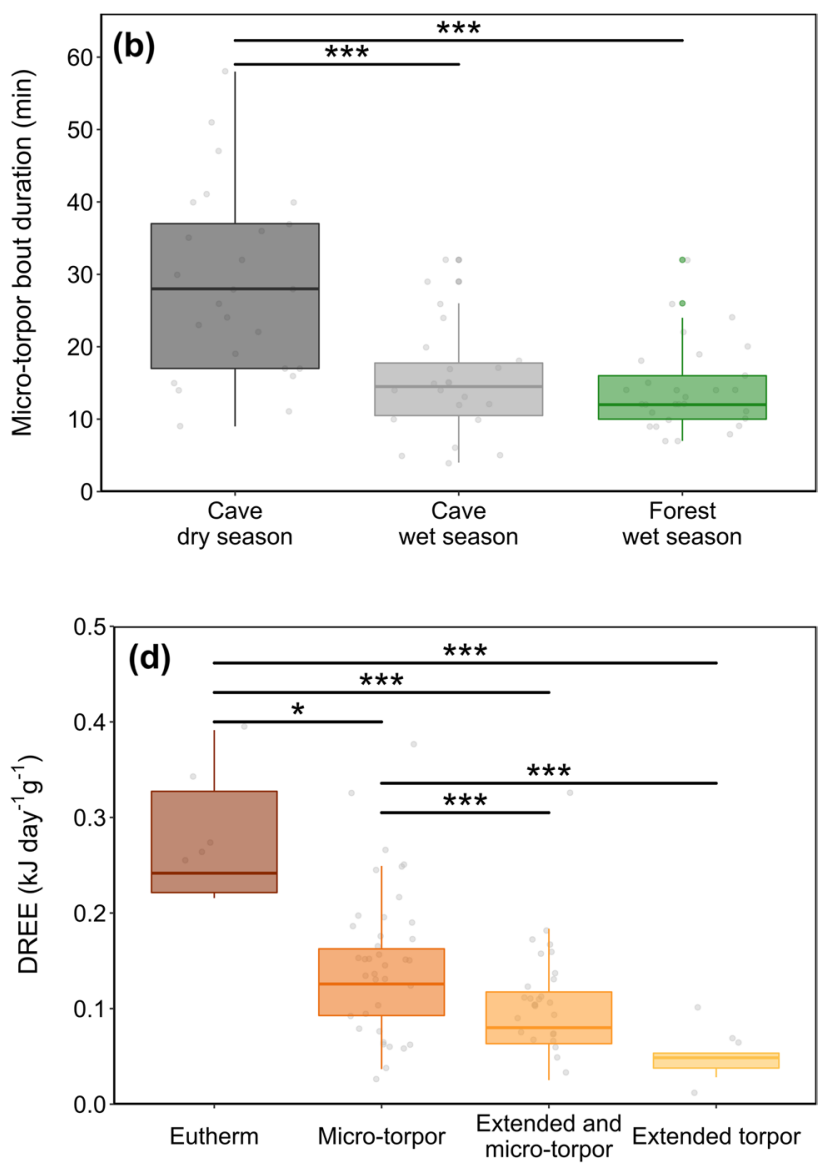

together with a more extended torpor bout, light orange; entering extended torpor, yellow). In all plots, the centre line represents the median, box limits indicate upper and lower quartiles, whiskers show $1.5 \times$ interquartile range and grey points are all data included; significant differences are marked with asterisks $\left({ }^{*} p \leq 0.05 ; * * p<0.01\right.$; $* * * p<0.001)$ 
We did not analyse the frequency of extended torpor bouts because the bats usually only entered one extended bout per day. Under all three different environmental conditions, the ratio of males entering extended torpor was always higher than females (cave dry season: females 50\%, males $75 \%$; cave wet season: females $11 \%$, males $83 \%$; forest wet season: females $89 \%$, males $100 \%$; Table 2).

\section{Daytime resting energy expenditure (DREE)}

The physiological strategy used by the bats was the only significant predictor for total energy expenditure during daytime rest (DREE; $\mathrm{Chi}^{2}=38.12, p<0.001, N=39, n=83$ ), i.e. either remaining euthermic $\left(0.26 \pm 0.10 \mathrm{~kJ} \mathrm{day}^{-1} \mathrm{~g}^{-1}\right)$, entering micro-torpor bouts $\left(0.14 \pm 0.06 \mathrm{~kJ} \mathrm{day}^{-1} \mathrm{~g}^{-1}\right)$, entering micro-torpor bouts together with an extended torpor bout $\left(0.09 \pm 0.05 \mathrm{~kJ} \mathrm{day}^{-1} \mathrm{~g}^{-1}\right)$ or only entering extended torpor $\left(0.05 \pm 0.03 \mathrm{~kJ} \mathrm{day}^{-1} \mathrm{~g}^{-1}\right.$; Fig. $\left.5 \mathrm{~d}\right)$. In this order, each response saved approximately $46 \%$ $(z$-ratio $=2.62, p<0.043), 65 \%(z$-ratio $=3.83, p<0.001)$ and $81 \%(z$-ratio $=4.01, p<0.001)$ of the energy expended during a day remaining euthermic (Fig. 5d). Sex ( $t=0.73$, $p=0.468)$, body condition $(t=-1.05, p=0.294)$ and siteseason $\left(C h i^{2}=5.77, p=0.056\right)$ had no effect on DREE. However, the cave population in the wet season had a higher DREE than the other bats (cave wet vs. cave dry season: $z$-ratio $=-17.63, p<0.001$; cave wet vs. forest wet season: $z$-ratio $=-10.80, p<0.001$; cave dry vs. forest wet season: $z$-ratio $=-1.43, p=0.094 ;$ Table 2 ).

\section{Discussion}

The two populations of $M$. commersoni studied showed variation in their physiological responses to environmental conditions experienced while roosting in contrasting habitat types. For both populations, torpor was a key response used to finely balance energy expenditure. While metabolic rate during rest and during torpor were both similar across roosts, torpor timing, duration and frequency were flexibly adjusted to prevailing $T_{\mathrm{a}}$ and $\mathrm{RH}_{\mathrm{a}}$.

Surprisingly, cave-dwelling bats used relatively low rates of torpor in the resource-poor and cooler dry season. During this time of the year, the bats rarely leave their cave for months and food availability is drastically reduced (Razakarivony et al. 2005; Goodman 2006; Rakotoarivelo et al. 2007; Reher et al. 2019). Hence, we hypothesised that bats roosting in the cave would hibernate and show prolonged torpor (i.e., torpor bouts $>24 \mathrm{~h}$ in duration) most often. Instead, only $60 \%$ of these individuals entered extended torpor and $80 \%$ used repetitive micro-torpor bouts, which was less than during the warmer, more abundant wet season (93\%) or site (100\%). Only one measured individual entered a multi-day torpor bout and it appears to be common that several strategies, i.e. hibernation (multiday torpor), extended torpor, micro-torpor and no torpor, are used by different individuals within the same population in this species (Reher et al. 2018; Dausmann et al. in press). This variability was also observed in the Malagasy mouse lemur Microcebus griseorufus (Kobbe et al. 2011). Interestingly, the timing of both extended and micro-torpor occurred randomly throughout the day unlike during the wet season, when bats left the cave at dusk. Photoperiod is often a stimulus for torpor timing but in the absence of light $T_{\mathrm{a}}$ can also act as an important Zeitgeber (Heldmaier et al. 1982; Körtner and Geiser 2000). In Andranolovy Cave, however, $T_{\mathrm{a}}$ and $\mathrm{RH}_{\mathrm{a}}$ were relatively constant. Animals living in a constant environment like this can experience shifts in their circadian rhythm. For instance, patterns of activity become arrhythmic in arctic mammals when they are confronted with continuous dark or light conditions (van Oort et al. 2005; Appenroth et al. 2021) and circadian patterns in the timing of arousal from torpor are lost in some hibernators (e.g., Körtner and Geiser 2000; Revel et al. 2007; Williams et al. 2017). The loss of circadian rhythmicity in torpor timing therefore supports the notion that these bats cease foraging during this time of year (Razakarivony et al. 2005; Goodman 2006; Rakotoarivelo et al. 2007; Reher et al. 2019), even though it is likely that not all were hibernating. We suggest that a stable microclimate within the bat's thermal neutral zone (32-36 ${ }^{\circ} \mathrm{C}$; Reher and Dausmann 2021; this study), i.e. the $T_{\mathrm{a}}$-range at which no active thermoregulatory support is needed to maintain euthermic $T_{\mathrm{b}}$, permits an overwintering strategy fuelled by large fat deposits without the need for long-term hypometabolism.

Ample food resources are available in the wet season, making longer torpor bouts unnecessary. Less time spent torpid, and thus longer active periods, benefit social interaction in a large colony (Kunz and Lumsden 2003). The cave-dwelling bats we studied used fewer extended torpor bouts in the wet season (40\% of individuals) and these bouts were shorter than during the dry season or in the forest. Three out of six animals using extended torpor in the cave were measured when the outer fringes of a cyclone crossed the region and the colony did not leave the cave for several days. Torpor is a powerful response for enduring extreme weather events such as droughts, heatwaves, storms and fires (Doucette et al. 2012; Bondarenco et al. 2014; Nowack et al. 2015; Stawski et al. 2015). Moreover, it can also be advantageous in better-resourced seasons (Heldmaier et al. 2004; Geiser and Brigham 2012); for example, short torpor bouts can compensate for unsuccessful foraging (Heldmaier et al. 2004) or speed up pre-hibernation fattening (Giroud et al. 2012). Because $M$. commersoni accumulates fat at the end of the wet season (Goodman 2006; Jenkins and Racey 2008), 
extended torpor may be used flexibly on an individual basis or to get through environmental bottlenecks.

In contrast, forest-roosting bats made considerable use of torpor in the wet season ( $94 \%$ of individuals), which was more than the cave bats regardless of season $(60 \%$ of individuals in the dry season and $40 \%$ in the wet season). Furthermore, extended torpor bouts used by forest bats in the wet season were as long as those used by dry season cave bats. This was unexpected because the foliage used for roosting did not offer protection from predators or daytime extremes of high $T_{\mathrm{a}}$ or low $\mathrm{RH}_{\mathrm{a}}$. Water loss is presumably high under these conditions, as insensible water loss increases as ambient water vapour pressure decreases (Mitchell et al. 2018; but see Cooper and Withers 2017) and the maximum difference in $\mathrm{RH}_{\mathrm{a}}$ between the cave and forest was $65 \%$ (cave: never below $94 \% \mathrm{RH}_{\mathrm{a}}$, forest: down to $29 \%$ $\mathrm{RH}_{\mathrm{a}}$ after noon). During torpor water loss can be reduced by over $90 \%$ compared to euthermia, because water-consuming processes such as respiration, urine production and defecation are downregulated or even stopped (Morris et al. 1994; Webb et al. 1995; Muñoz-Garcia et al. 2012; Levin et al. 2015; Hill et al. 2016). Indeed, the timing of longer torpor bouts in $M$. commersoni is related to times when $T_{\mathrm{a}}$ exceeds euthermic $T_{\mathrm{b}}$ (Reher and Dausmann 2021). Above this threshold, only evaporative cooling can regulate $T_{\mathrm{b}}$, which is unfavourable in a dry region if water reserves are unable to be replenished (Mitchell et al. 2018). Entering torpor at high $T_{\mathrm{a}}$ reduces metabolic heat and water production, allowing higher rates of heat from the environment to be stored in the body via facultative hyperthermia (Lovegrove et al. 2014; Welman et al. 2017; Reher and Dausmann 2021). Compared to the bats roosting in the cave at near stable conditions, it appears the forest bats in our study used this strategy to mitigate heat and water stress.

In addition to modulating torpor frequency and duration, heterotherms can adjust the level of metabolic reduction to reduce the costs of torpor while maximising the benefits (Boyles et al. 2020). The mean reduction in eTMR from euthermia (80-89\%) and mTMR (73-79\%) was relatively similar among the different roosting conditions. Given that $T_{\text {skin }}$ during torpor ranged between $33.0^{\circ} \mathrm{C}$ in the cave and $38.5^{\circ} \mathrm{C}$ in the forest (total range: $24.6-42.9{ }^{\circ} \mathrm{C}$ ), this reduction in MR is remarkable and among the highest reported for warm environments (25-84\%; Song et al. 1997; Dausmann et al. 2009; Grimpo et al. 2013; Kobbe et al. 2014). The observed variability in metabolic depression reflects the $T_{\mathrm{a}}$ fluctuations at each roost. Bats were torpid at a higher $T_{\mathrm{a}}$, and therefore $T_{\mathrm{b}}$, in the forest than in the cave. The forest and cave bats had a similar TMR at the same $T_{a}$, comparable to Kuhl's pipistrelle and big brown bats that also display a TMR that varies very little between populations roosting under different climatic conditions (Klüg-Baerwald and Brigham 2017; Gearhart et al. 2020). Therefore, the level of metabolic depression at a given $T_{\mathrm{a}}$ appears to be less plastic than torpor pattern variation in these bats (but see Dunbar and Brigham 2010). It is worth noting, however, that we excluded one individual that entered a multi-day torpor bout from analyses. The body condition of this individual was among the poorest $20 \%$ of bats in this study and it reduced MR by $94 \%$ at a $T_{\text {skin }}$ of $33{ }^{\circ} \mathrm{C}$. TMR during multi-day torpor is lower than during daily torpor (Geiser 2004) and it is possible that this individual entered a multi-day torpor bout to maximise energetic savings and slow the depletion of its meagre fat reserves (Humphries et al. 2003; Jonasson and Willis 2011).

Macronycteris commersoni appeared to avoid longer torpor bouts when energy or water conservation were not vital. Instead, they entered the shortest torpor bouts of any heterotherm studied so far. All but three cave-dwelling individuals used micro-torpor bouts with patterns reflecting prevailing environmental conditions, appearing to be the preferred mode of torpor. Micro-torpor bouts were less frequent but longer during the dry season than the wet season. They were especially frequent in cave bats during the wet season and in the forest they were used in combination with an extended torpor bout on hot days (Reher and Dausmann 2021). Microtorpor bouts combine an increased number of active phases, and thus higher vigilance, with energy and water savings. This could enable bats in exposed roosts in foliage to react quickly to threats and be beneficial in caves for maintaining social and territorial activities (Kunz and Lumsden 2003). However, micro-torpor usually occurred in a repetitive manner (12.0 \pm 6.9 consecutive bouts), increasing not only the number of active periods but also the number of arousal phases. Arousing from torpor is potentially harmful, especially at low $T_{\mathrm{a}}$, because it increases oxidative stress and can cause cellular damage (Carey et al. 2003; Brown and Staples 2011; Nowack et al. 2019). Interestingly, Australian desert bats can arouse from torpor passively without active thermogenesis when $T_{\mathrm{a}}$ is near euthermic $T_{\mathrm{b}}$ (Bondarenco et al. 2013) and the energetic costs of rewarming from torpor for long-eared bats are reduced at higher $T_{\mathrm{a}}$ (Currie et al. 2014). Since M. commersoni MR during an arousal period rarely exceeded RMR, we assume that the costs of arousing at thermoneutrality are negligible, making micro-torpor an effective strategy.

Flexible torpor expression helped M. commersoni cope with different roosting conditions but torpor use in general comes with potential costs (reviewed in Landes et al. 2020). These include reduced responsiveness to the environment, missed opportunities for reproduction, reduced territory defence (Choi et al. 1998; Mzilikazi and Lovegrove 2002), cellular damage, diminished immune function and memory loss during hibernation (Millesi et al. 2001; Carey et al. 2003; Bouma et al. 2010). Energy and water can also be conserved by adjusting RMR; many mammals shift their 
TNZ in response to seasonal changes in $T_{\mathrm{a}}$ to reduce energy expenditure during euthermia (Lovegrove 2005). We did not find any differences between roosts or seasons in overall RMR or RMR at overlapping $T_{\mathrm{a}}$. This is unsurprising within the cave roost because it offers stable ambient conditions year-round. However, the lack of difference in RMR between the cave and forest roosts is unexpected, given the large fluctuations in $T_{\mathrm{a}}$ in the forest. The forest population has a TNZ between $\sim 32-36{ }^{\circ} \mathrm{C}$ in the wet season (Reher and Dausmann 2021); while we were unable to determine the cave population's TNZ due to very stable conditions, we would suspect their TNZ to be close to the cave's $32{ }^{\circ} \mathrm{C}$. Thus, our measurements were probably below their thermal neutral conditions, suggested by the steeper slope in RMR. A more experimentally driven approach examining the bats' responses under controlled conditions may consequently uncover geographical and seasonal variation in RMR.

Despite marked environmental differences between seasons and sites, bat body condition was similar among groups. Only forest-dwelling females had lower body condition than other bats, but sex was only a predictor for microtorpor bout frequency and body condition only a predictor of extended torpor bout duration in the models. Since little is known about $M$. commersoni in general, we speculate that possibly younger, leaner females were present in the study or that reproduction is much more costly in the forest. We conducted the wet season measurements between midFebruary and the end of March to keep seasonal life-history differences low, but it is likely that some females were still recuperating the costs of recent reproductive activities (in the cave, females wean their offspring in January; pers. obs.). In the wet season, DREE in the forest was $\sim 1.6$ times lower than in the cave and as low as in the cave in the dry season. This was largely due to the use of extended torpor as a response to heat; flexible torpor use dictated energy expenditure and not roosting conditions per se. For example, using several repeated micro-torpor bouts throughout the day reduced DREE by $46 \%$ compared to remaining euthermic; several micro-bouts combined with extended torpor bouts reduced DREE by $65 \%$ and entering a single, even longer extended torpor bout reduced DREE by $81 \%$. Individual bats could balance DREE and body condition by adjusting bout duration and frequency. This strategy, combined with the insignificant costs of arousal from torpor at high $T_{\mathrm{b}}$, equips M. commersoni with a versatile physiological toolbox. Its broad repertoire allows the regulation of energy consumption and water depletion in direct response to prevailing conditions at a fine scale. This enables the species to effectively compensate for variable environmental pressures, and roost under contrasting ambient conditions, with little to no variation in body condition.

Our findings stress that physiological traits are not fixed within a species over seasonal and geographic scales. While there are many published studies of seasonal physiological variation (e.g. Brigham et al. 2000; Stawski and Geiser 2010; Czenze et al. 2017a), fewer examples exist investigating how separate populations of the same species cope with different environmental pressures (e.g., Dunbar and Brigham 2010; Stawski 2012; Noakes et al. 2016; Czenze et al. 2017b; van Jaarsveld et al. 2021). In a region like Madagascar, where almost $44 \%$ of the endemic vertebrate fauna are endangered or facing extinction (i.e., classified vulnerable or worse; IUCN 2021), it is of utmost importance to understand the entire range of variability within species' ecophysiological traits. The variation in physiological traits that we observed for $M$. commersoni, for example, allows it to roost under vastly different environmental conditions, which has likely contributed to its successful colonisation of a range of habitat types distributed across almost all of Madagascar. Whether the variation uncovered in our study is related to phenotypic flexibility and can be expressed by individual $M$. commersoni, or whether these are local adaptations of each population, remains unclear (Geiser and Ferguson 2001; Dunbar and Brigham 2010). Nonetheless, our results demonstrate that conclusions drawn from limited datasets may not accurately represent a species as a whole. Studying more than one population and at different times of the year is logistically and financially challenging. However, this can illuminate intraspecific physiological, behavioural or morphological variation and ultimately give a clearer picture of a species' potential for enduring a range of environmental pressures. Such insight is vital for predicting the consequences of disturbance events or rapid climatic changes and ensuring that conservation and species management actions do not fall short of their targets in regions with high environmental variability.

Supplementary Information The online version contains supplementary material available at https://doi.org/10.1007/s00442-021-05088-2.

Acknowledgements We thank Robert Jean Niry, Arne Wulff and the team of the association Analasoa for their constant help during fieldwork and Jörg Ganzhorn for permission to use the research Camp Andranovao in Tsimanampetsotse National Park. We are grateful to Peter Kappeler and Claudia Fichtel for allowing us to operate from, and use the facilities of, the field station of the German Primate Centre (DPZ). The Centre National de Formation d'Etude et de Recherche en Environment et Foresterie (CNFEREF) supported our fieldwork in Kirindy. We highly appreciate the help of Jacques Rakotondranary and Yedidia Rakotomalala Ratovonamana with the organisation of logistics and authorisations, Steve Goodman's expertise in a variety of Malagasy bat-related topics, Janina Bethge's general support and the reviewers' helpful feedback improving the manuscript.

Author contribution statement SR and KHD designed the study. SR and HR carried out fieldwork, SR and BKM analysed the data, and SR wrote the first draft of the manuscript. SR, KHD, BKM and JMT discussed and interpreted the results, revised and edited the manuscript. All authors read and approved the final version of the manuscript. 
Funding Open Access funding enabled and organized by Projekt DEAL. The German Research Foundation (DA 1013/7-1) and IDEA WILD (REHEMADA1116) supported this work financially.

Availability of data and material All data analysed during the current study are available from the corresponding author on reasonable request.

\section{Declarations}

Conflict of interest The authors declare that they have no conflict of interest.

Ethics statement This study was conducted under the "Accord de Collaboration" between Université d'Antananarivo (Département de Biologie Animale), Madagascar National Parks and Universität Hamburg. We thank these authorities and the Ministère de l'Environnement, de l'Ecologie et des Forêts for support and project authorisation. The research was approved by the Directeur du Système des Aires Protégées, Ministère de l'Environnement, Antananarivo (Autorisation de recherche no. 90/16/MEEMF/SG/DGF/DAPT/SCBT.Re, $003 \&$ 296/17/MEEF/SG/DGF/DSAP/SCB.Re) and all described procedures comply with the current ethical regulations and laws of Madagascar for the care and use of animals.

Open Access This article is licensed under a Creative Commons Attribution 4.0 International License, which permits use, sharing, adaptation, distribution and reproduction in any medium or format, as long as you give appropriate credit to the original author(s) and the source, provide a link to the Creative Commons licence, and indicate if changes were made. The images or other third party material in this article are included in the article's Creative Commons licence, unless indicated otherwise in a credit line to the material. If material is not included in the article's Creative Commons licence and your intended use is not permitted by statutory regulation or exceeds the permitted use, you will need to obtain permission directly from the copyright holder. To view a copy of this licence, visit http://creativecommons.org/licenses/by/4.0/.

\section{References}

Aldridge HDJN, Brigham RM (1988) Load carrying and maneuverability in an insectivorous bat: a test of the 5\% "rule" of radio-telemetry. J Mammal 69:379-382. https://doi.org/10. 2307/1381393

Appenroth D, Nord A, Hazlerigg DG, Wagner GC (2021) Body temperature and activity rhythms under different photoperiods in high Arctic Svalbard ptarmigan (Lagopus muta hyperborea). Front Physiol 12:633866. https://doi.org/10.3389/fphys.2021. 633866

Audet D, Thomas DW (1996) Evaluation of the accuracy of body temperature measurement using external radio transmitters. Can J Zool 74:1778-1781. https://doi.org/10.1139/z96-196

Bates D, Mächler M, Bolker B, Walker S (2015) Fitting linear mixedeffects models using lme4. J Stat Softw 67:1-48. https://doi.org/ 10.18637/jss.v067.i01

Bethge J, Wist B, Stalenberg E, Dausmann K (2017) Seasonal adaptations in energy budgeting in the primate Lepilemur leucopus. J Comp Physiol B 187:827-834. https://doi.org/10.1007/ s00360-017-1082-9

Bondarenco A, Körtner G, Geiser F (2013) Some like it cold: summer torpor by freetail bats in the Australian arid zone. J Comp
Physiol B 183:1113-1122. https://doi.org/10.1007/s00360-0130779-7Physiol.Zool

Bondarenco A, Körtner G, Geiser F (2014) Hot bats: extreme thermal tolerance in a desert heat wave. Sci Nat 101:679-685. https://doi. org/10.1007/s00114-014-1202-2

Bouma HR, Carey HV, Kroese FGM (2010) Hibernation: the immune system at rest? J Leukoc Biol 88:619-624. https://doi.org/10. 1189/jlb.0310174

Boyles JG, Johnson JS, Blomberg A, Lilley TM (2020) Optimal hibernation theory. Mammal Rev 50:91-100. https://doi.org/10.1111/ mam.12181

Bozinovic F, Calosi P, Spicer JI (2011) Physiological correlates of geographic range in animals. Annu Rev Ecol Evol Syst 42:155179. https://doi.org/10.1146/annurev-ecolsys-102710-145055

Brigham RM, Körtner G, Maddocks TA, Geiser F (2000) Seasonal use of torpor by free-ranging Australian owlet-nightjars (Aegotheles cristatus). Physiol Biochem Zool 73:613-620. https://doi.org/10.1086/317755

Brooks ME, Kristensen K, van Benthem J, K, et al (2017) glmmTMB balances speed and flexibility among packages for zero-inflated generalized linear mixed modeling. R J 9:378-400

Brown JCL, Staples JF (2011) Mitochondrial metabolic suppression in fasting and daily torpor: consequences for reactive oxygen species production. Physiol Biochem Zool 84:467-480. https:// doi.org/10.1086/661639

Canale C, Henry P (2010) Adaptive phenotypic plasticity and resilience of vertebrates to increasing climatic unpredictability. Clim Res 43:135-147. https://doi.org/10.3354/cr00897

Carey HV, Andrews MT, Martin SL (2003) Mammalian hibernation: cellular and molecular responses to depressed metabolism and low temperature. Physiol Rev 83:1153-1181. https://doi.org/ 10.1152/physrev.00008.2003

Choi I, Cho Y, Oh YK et al (1998) Behavior and muscle performance in heterothermic bats. Physiol Zool 71:257-266. https://doi. org/10.1086/515915

Cooke SJ, Sack L, Franklin CE et al (2013) What is conservation physiology? Perspectives on an increasingly integrated and essential science. Conserv Physiol 1:1-23. https://doi.org/10. 1093/conphys/cot001

Cooper CE, Withers PC (2002) Metabolic physiology of the numbat (Myrmecobius fasciatus). J Comp Physiol B 172:669-675. https://doi.org/10.1007/s00360-002-0294-8

Cooper CE, Withers PC (2017) Thermoregulatory role of insensible evaporative water loss constancy in a heterothermic marsupial. Biol Lett 13:20170537. https://doi.org/10.1098/rsbl.2017.0537

Cooper CE, Withers PC, Munns SL et al (2018) Geographical variation in the standard physiology of brushtail possums (Trichosurus): implications for conservation translocations. Conserv Physiol. https://doi.org/10.1093/conphys/coy042

Currie SE, Noy K, Geiser F (2014) Passive rewarming from torpor in hibernating bats: minimizing metabolic costs and cardiac demands. Am J Physiol Regul Integr Comp Physiol 308:R34R41. https://doi.org/10.1152/ajpregu.00341.2014

Czenze ZJ, Brigham RM, Hickey AJR, Parsons S (2017a) Cold and alone? Roost choice and season affect torpor patterns in lesser short-tailed bats. Oecologia 183:1-8. https://doi.org/10.1007/ s00442-016-3707-1

Czenze ZJ, Brigham RM, Hickey AJR, Parsons S (2017b) Stressful summers? Torpor expression differs between high- and lowlatitude populations of bats. J Mammal 98:1249-1255. https:// doi.org/10.1093/jmammal/gyx071

Dausmann KH (2005) Measuring body temperature in the fieldevaluation of external vs. implanted transmitters in a small mammal. J Therm Biol 30:195-202. https://doi.org/10.1016/j. jtherbio.2004.11.003 
Dausmann KH, Glos J, Heldmaier G (2009) Energetics of tropical hibernation. J Comp Physiol B 179:345-357. https://doi.org/ 10.1007/s00360-008-0318-0

Dausmann KH, Reher S, Bethge J (in press) Heterothermy in Malagasy Mammals. In: Goodman SM, (ed) The new natural history of Madagascar. Princeton University Press, Princeton

Doucette LI, Brigham RM, Pavey CR, Geiser F (2012) Prey availability affects daily torpor by free-ranging Australian owletnightjars (Aegotheles cristatus). Oecologia 169:361-372. https://doi.org/10.1007/s00442-011-2214-7

Dunbar MB, Brigham RM (2010) Thermoregulatory variation among populations of bats along a latitudinal gradient. J Comp Physiol B 180:885-893. https://doi.org/10.1007/s00360-010-0457-y

Fenton MB, Rautenbach IL, Smith SE et al (1994) Raptors and bats: threats and opportunities. Anim Behav 48:9-18. https://doi.org/ 10.1006/anbe.1994.1207

Gearhart C, Adams AM, Pinshow B, Korine C (2020) Evaporative water loss in Kuhl's pipistrelles declines along an environmental gradient, from mesic to hyperarid. Comp Biochem Physiol A Mol Integr Physiol 240:110587. https://doi.org/10.1016/j.cbpa. 2019.110587

Geiser F (2004) Metabolic rate and body temperature reduction during hibernation and daily torpor. Annu Rev Physiol 66:239-274. https://doi.org/10.1146/annurev.physiol.66.032102.115105

Geiser F, Brigham RM (2012) The other functions of torpor. In: Ruf T, Bieber C, Arnold W, Millesi E (eds) Living in a seasonal world: thermoregulatory and metabolic adaptations. Springer, Berlin, Heidelberg, pp 109-121

Geiser F, Ferguson C (2001) Intraspecific differences in behaviour and physiology: effects of captive breeding on patterns of torpor in feathertail gliders. J Comp Physiol B 171:569-576. https://doi. org/10.1007/s003600100207

Geiser F, Stawski C (2011) Hibernation and torpor in tropical and subtropical bats in relation to energetics, extinctions, and the evolution of endothermy. Integr Comp Biol 51:337-348. https:// doi.org/10.1093/icb/icr042

Geiser F (2021) Ecological physiology of daily torpor and hibernation. Springer Nature, Cham, Switzerland

Giroud S, Turbill C, Ruf T (2012) Torpor use and body mass gain during pre-hibernation in late-born juvenile garden dormice exposed to food shortage. In: Ruf T, Bieber C, Arnold W, Millesi E (eds) Living in a seasonal world: thermoregulatory and metabolic adaptations. Springer, Berlin, Heidelberg, pp 481-491

Glotzbach S, Heller H (1976) Central nervous regulation of body temperature during sleep. Science 194:537-539. https://doi.org/10. 1126/science. 973138

Goodman SM (2006) Hunting of microchiroptera in south-western Madagascar. Oryx 40:225-228. https://doi.org/10.1017/S0030 605306000354

Goodman S, Raherilalao M, Wohlhauser S (2018) Les aires protégées terrestres de Madagascar : Leur histoire, description et biote / The terrestrial protected areas of Madagascar: their history, description, and biota. Association Vahatra, Antananarivo

Goodman SM (2011) Les chauves-souris de Madagascar: guide de leur distribution, biologie et identification. Association Vahatra, Antananarivo

Grimpo K, Legler K, Heldmaier G, Exner C (2013) That's hot: golden spiny mice display torpor even at high ambient temperatures. J Comp Physiol B 183:567-581. https://doi.org/10.1007/ s00360-012-0721-4

Grolemund G, Wickham H (2011) Dates and times made easy with lubridate. J Stat Softw 40:1-25. https://doi.org/10.18637/jss. v040.i03

Heldmaier G, Steinlechner S, Rafael J, Latteier B (1982) Photoperiod and ambient temperature as environmental cues for seasonal thermogenic adaptation in the Djungarian hamster, Phodopus sungorus. Int J Biometeorol 26:339-345. https://doi.org/10.1007/ BF02219505

Heldmaier G, Ortmann S, Elvert R (2004) Natural hypometabolism during hibernation and daily torpor in mammals. Respir Physiol Neurobiol 141:317-329. https://doi.org/10.1016/j.resp.2004.03. 014

Heller HC (1988) Sleep and hypometabolism. Can J Zool 66:61-69. https://doi.org/10.1139/z88-008

Hill R, Wyse GA, Anderson M (2016) Animal Physiology. Sinauer, Sunderland, Massachusetts

Hume T, Geiser F, Currie SE et al (2020) Responding to the weather: energy budgeting by a small mammal in the wild. Curr Zool 66:15-20. https://doi.org/10.1093/cz/zoz023

Humphrey SR (1975) Nursery roosts and community diversity of Nearctic bats. J Mammal 56:321-346. https://doi.org/10.2307/ 1379364

Humphries MM, Thomas DW, Kramer DL (2003) The role of energy availability in mammalian hibernation: a cost-benefit approach. Physiol Biochem Zool 76:165-179. https://doi.org/10.1086/ 367950

Irwin MT, Wright PC, Birkinshaw C et al (2010) Patterns of species change in anthropogenically disturbed forests of Madagascar. Biol Conserv 143:2351-2362. https://doi.org/10.1016/j.biocon. 2010.01.023

IUCN (2021) The IUCN Red List of Threatened Species. Version 2021-1. https://www.iucnredlist.org

Jammalamadaka SR, Sengupta A (2001) Topics in circular statistics. World Scientific Publishing, Singapore

Jenkins R, Racey P (2008) Bats as bushmeat in Madagascar. Madag Conserv Dev 3:22-30. https://doi.org/10.4314/mcd.v3i1.44132

Jonasson KA, Willis CKR (2011) Changes in body condition of hibernating bats support the thrifty female hypothesis and predict consequences for populations with white-nose syndrome. PLoS ONE 6:e21061. https://doi.org/10.1371/journal.pone.0021061

Kappeler PM, Fichtel C (2012) A 15-Year perspective on the social organization and life history of sifaka in Kirindy Forest. In: Kappeler PM, Watts DP (eds) Long-term field studies of primates. Springer, Berlin Heidelberg, pp 101-121

Kassambara, A (2020a). ggpubr: 'ggplot2' based publication ready plots. R package version 0.4.0. https://CRAN.R-project.org/ package $=$ ggpubr

Kassambara, A (2020b). rstatix: pipe-friendly framework for basic statistical tests. R package version 0.6.0. https://CRAN.R-project. org $/$ package $=$ rstatix

Klüg-Baerwald BJ, Brigham RM (2017) Hung out to dry? Intraspecific variation in water loss in a hibernating bat. Oecologia 183:977985. https://doi.org/10.1007/s00442-017-3837-0

Kobbe S, Ganzhorn JU, Dausmann KH (2011) Extreme individual flexibility of heterothermy in free-ranging Malagasy mouse lemurs (Microcebus griseorufus). J Comp Physiol B 181:165-173. https://doi.org/10.1007/s00360-010-0507-5

Kobbe S, Nowack J, Dausmann KH (2014) Torpor is not the only option: seasonal variations of the thermoneutral zone in a small primate. J Comp Physiol B 184:789-797. https://doi.org/10. 1007/s00360-014-0834-z

Körtner G, Geiser F (2000) The temporal organization of daily torpor and hibernation: circadian and circannual rhythms. Chronobiol Int 17:103-128. https://doi.org/10.1081/CBI-100101036

Kunz TH (1982) Roosting Ecology of Bats. In: Kunz TH (ed) Ecology of Bats. Springer, Boston, pp 1-55

Kunz TH, Lumsden LF (2003) Ecology of cavity and foliage roosting bats. In: Kunz TH, Fenton MB (eds) Bat Ecology. The University of Chicago Press, Chicago and London, pp 3-89

Kuznetsova A, Brockhoff PB, Christensen RHB (2017) lmerTest Package: tests in linear mixed effects models. J Stat Softw 82:1-26. https://doi.org/10.18637/jss.v082.i13 
Landes J, Pavard S, Henry P-Y, Terrien J (2020) Flexibility is costly: hidden physiological damage from seasonal phenotypic transitions in heterothermic species. Front Physiol 11:985. https://doi. org/10.3389/fphys.2020.00985

Langer F, Fietz J (2014) Ways to measure body temperature in the field. J Therm Biol 42:46-51. https://doi.org/10.1016/j.jtherbio. 2014.03.002

Lenth RV (2021) emmeans: estimated marginal means, aka leastsquares means. R package version 1.7.0. https://CRAN.R-proje ct.org/package $=$ emmeans

Levin E, Plotnik B, Amichai E et al (2015) Subtropical mouse-tailed bats use geothermally heated caves for winter hibernation. Proc R Soc B 282:20142781. https://doi.org/10.1098/rspb.2014.2781

Lighton JRB (2008) Measuring metabolic rates: a manual for scientists. Oxford University Press, Oxford

Lovegrove BG (2005) Seasonal thermoregulatory responses in mammals. J Comp Physiol B 175:231-247. https://doi.org/10.1007/ s00360-005-0477-1

Lovegrove BG, Canale C, Levesque D et al (2014) Are tropical small mammals physiologically vulnerable to Arrhenius effects and climate change? Physiol Biochem Zool 87:30-45. https://doi. org/10.1086/673313

McGuire LP, Fuller NW, Dzal YA et al (2021) Similar hibernation physiology in bats across broad geographic ranges. J Comp Physiol B. https://doi.org/10.1007/s00360-021-01400-x

Millesi E, Prossinger H, Dittami JP, Fieder M (2001) Hibernation effects on memory in European ground squirrels (Spermophilus citellus). J Biol Rhythms 16:264-271

Mitchell D, Snelling EP, Hetem RS et al (2018) Revisiting concepts of thermal physiology: predicting responses of mammals to climate change. J Anim Ecol 87:956-973. https://doi.org/10.1111/ 1365-2656.12818

Morris S, Curtin AL, Thompson MB (1994) Heterothermy, torpor, respiratory gas exchange, water balance and the effect of feeding in Gould's long-eared bat Nyctophilus gouldi. J Exp Biol 197:309-335. https://doi.org/10.1242/jeb.197.1.309

Muñoz-Garcia A, Ro J, Reichard JD et al (2012) Cutaneous water loss and lipids of the stratum corneum in two syntopic species of bats. Comp Biochem Physiol Part A Mol Integr Physiol 161:208-215. https://doi.org/10.1016/j.cbpa.2011.10.025

Mzilikazi N, Lovegrove BG (2002) Reproductive activity influences thermoregulation and torpor in pouched mice, Saccostomus campestris. J Comp Physiol B 172:7-16. https://doi.org/10.1007/ s003600100221

Noakes MJ, McKechnie AE (2020) Phenotypic flexibility of metabolic rate and evaporative water loss does not vary across a climatic gradient in an Afrotropical passerine bird. J Exp Biol. https://doi. org/10.1242/jeb.220137

Noakes MJ, Wolf BO, McKechnie AE (2016) Seasonal and geographical variation in heat tolerance and evaporative cooling capacity in a passerine bird. J Exp Biol. https://doi.org/10.1242/jeb.132001

Nowack J, Rojas AD, Körtner G, Geiser F (2015) Snoozing through the storm: torpor use during a natural disaster. Sci Rep 5:11243. https://doi.org/10.1038/srep11243

Nowack J, Tarmann I, Hoelzl F et al (2019) Always a price to pay: hibernation at low temperatures comes with a trade-off between energy savings and telomere damage. Biol Lett 15:20190466. https://doi.org/10.1098/rsbl.2019.0466

Nowack J, Levesque DL, Reher S, Dausmann KH (2020) Variable climates lead to varying phenotypes: 'weird' mammalian torpor and lessons from non-Holarctic species. Front Ecol Evol 8:60. https://doi.org/10.3389/fevo.2020.00060

Peig J, Green AJ (2009) New perspectives for estimating body condition from mass/length data: the scaled mass index as an alternative method. Oikos 118:1883-1891. https://doi.org/10.1111/j. 1600-0706.2009.17643.x
Peig J, Green AJ (2010) The paradigm of body condition: a critical reappraisal of current methods based on mass and length. Funct Ecol 24:1323-1332. https://doi.org/10.1111/j.1365-2435.2010. 01751.x

R Development Core Team (2018) R: A language and environment for statistical computing. R Foundation for Statistical Computing.

Rakotoarivelo AA, Ranaivoson N, Ramilijaona OR et al (2007) Seasonal food habits of five sympatric forest Microchiropterans in western Madagascar. J Mammal 88:959-966. https://doi.org/10. 1644/06-MAMM-A-112R1.1

Ratovonamana RY, Rajeriarison C, Roger E et al (2013) Impact of livestock grazing on forest structure, plant species composition and biomass in southwestern Madagascar. Scr Bot Belgica 50:82-92

Razakarivony V, Rajemison B, Goodman SM (2005) The diet of Malagasy Microchiroptera based on stomach contents. Mamm Biol 70:312-316. https://doi.org/10.1016/j.mambio.2005.03.005

Rechtschaffen A (1998) Current perspectives on the function of sleep. Perspect Biol Med 41:359-390. https://doi.org/10.1353/pbm. 1998.0051

Reher S, Dausmann KH (2021) Tropical bats counter heat by combining torpor with adaptive hyperthermia. Proc R Soc B 288:20202059. https://doi.org/10.1098/rspb.2020.2059

Reher S, Ehlers J, Rabarison H, Dausmann KH (2018) Short and hyperthermic torpor responses in the Malagasy bat Macronycteris commersoni reveal a broader hypometabolic scope in heterotherms. J Comp Physiol B 188:1015-1027. https://doi.org/10. 1007/s00360-018-1171-4

Reher S, Rabarison H, Dausmann K (2019) Seasonal movements of insectivorous bat species in southwestern Madagascar. Malagasy Nat 13:117-124

Revel FG, Herwig A, Garidou M-L et al (2007) The circadian clock stops ticking during deep hibernation in the European hamster. PNAS 104:13816-13820. https://doi.org/10.1073/pnas.07046 99104

Rezende EL, Bacigalupe LD (2015) Thermoregulation in endotherms: physiological principles and ecological consequences. J Comp Physiol B 185:709-727. https://doi.org/10.1007/ s00360-015-0909-5

Richardson JL, Urban MC, Bolnick DI, Skelly DK (2014) Microgeographic adaptation and the spatial scale of evolution. Trends Ecol Evol 29:165-176. https://doi.org/10.1016/j.tree.2014.01.002

Rodgers E, Franklin CE (2021) Aerobic scope and climate warming: testing the "plastic floors and concrete ceilings" hypothesis in the estuarine crocodile (Crocodylus porosus). J Exp Zool A Ecol Integr Physiol 335:108-117. https://doi.org/10.1002/jez.2412

RStudio Team (2016) RStudio: Integrated development for R. RStudio Inc, Boston

Sagot M, Chaverri G (2015) Effects of roost specialization on extinction risk in bats. Conserv Biol 29:1666-1673. https://doi.org/ 10.1111/cobi.12546

Schmidt-Nielsen K (1997) Animal Physiology: Adaptation and Environment. Cambridge University Press, Cambridge

Solick DI, Barclay RMR (2006) Thermoregulation and roosting behaviour of reproductive and nonreproductive female western longeared bats (Myotis evotis) in the Rocky Mountains of Alberta. Can J Zool 84:589-599. https://doi.org/10.1139/z06-028

Song X, Körtner G, Geiser F (1997) Thermal relations of metabolic rate reduction in a hibernating marsupial. Am J Physiol Regul Integr Comp Physiol 273:R2097-R2104. https://doi.org/10.1152/ ajpregu.1997.273.6.R2097

Stawski C (2012) Comparison of variables of torpor between populations of a hibernating subtropical/tropical bat at different latitudes. In: Ruf T, Bieber C, Arnold W, Millesi E (eds) Living in a seasonal world: thermoregulatory and metabolic adaptations. Springer, Berlin, Heidelberg, pp 99-108 
Stawski C, Geiser F (2010) Seasonality of torpor patterns and physiological variables of a free-ranging subtropical bat. J Exp Biol 213:393-399. https://doi.org/10.1242/jeb.038224

Stawski C, Geiser F (2011) Do season and distribution affect thermal energetics of a hibernating bat endemic to the tropics and subtropics? Am J Physiol Regul Integr Comp Physiol 301:R542R547. https://doi.org/10.1152/ajpregu.00792.2010

Stawski C, Körtner G, Nowack J, Geiser F (2015) The importance of mammalian torpor for survival in a post-fire landscape. Biol Lett 11:20150134. https://doi.org/10.1098/rsbl.2015.0134

Thomas DW, Cloutier D, Gagné D (1990) Arrhythmic breathing, apnea and non-steady-state oxygen uptake in hibernating little brown bats (Myotis lucifugus). J Exp Biol 149:395-406

van Jaarsveld B, Bennett NC, Kemp R et al (2021) Heat tolerance in desert rodents is correlated with microclimate at inter- and intraspecific levels. J Comp Physiol B 191:575-588. https://doi. org/10.1007/s00360-021-01352-2

van Oort BEH, Tyler NJC, Gerkema MP et al (2005) Circadian organization in reindeer. Nature 438:1095-1096. https://doi.org/10. 1038/4381095a

Violle C, Enquist BJ, McGill BJ et al (2012) The return of the variance: intraspecific variability in community ecology. Trends Ecol Evol 27:244-252. https://doi.org/10.1016/j.tree.2011.11.014

Webb PI, Speakman JR, Racey PA (1995) Evaporative water loss in two sympatric species of vespertilionid bat, Plecotus auritus and Myotis daubentoni: relation to foraging mode and implications for roost site selection. J Zool 235:269-278. https://doi.org/10. 1111/j.1469-7998.1995.tb05143.x

Welman S, Tuen AA, Lovegrove BG (2017) Using thermoregulatory profiles to assess climate change vulnerability in an arboreal tropical bat: heterothermy may be a pre-adaptive advantage. Clim Res 74:161-170. https://doi.org/10.3354/cr01496

Wickham H (2011) The split-apply-combine strategy for data analysis. J Stat Softw 40:1-29. https://doi.org/10.18637/jss.v040.i01
Wickham H (2016) ggplot2: elegant graphics for data analysis. Springer-Verlag, New York

Wickham H, Bryan J (2017) readxl: Read excel files. R package version 1.3.1. https://CRAN.R-project.org/package $=$ readxl

Wickham H, François R, Henry L, Müller K (2020). dplyr: A grammar of data manipulation. R package version 1.0.2. https://CRAN.Rproject.org/package $=$ dplyr

Wilke CO (2020). cowplot: Streamlined plot theme and plot annotations for 'ggplot2'. R package version 1.1.0. https://CRAN.Rproject.org/package $=$ cowplot

Williams CT, Radonich M, Barnes BM, Buck CL (2017) Seasonal loss and resumption of circadian rhythms in hibernating arctic ground squirrels. J Comp Physiol B 187:693-703. https://doi.org/ 10.1007/s00360-017-1069-6

Willis CKR, Brigham RM (2003) Defining torpor in free-ranging bats: experimental evaluation of external temperature-sensitive radiotransmitters and the concept of active temperature. J Comp Physiol B 173:379-389. https://doi.org/10.1007/ s00360-003-0343-y

Willis CKR, Brigham RM (2004) Roost switching, roost sharing and social cohesion: forest-dwelling big brown bats, Eptesicus fuscus, conform to the fission-fusion model. Anim Behav 68:495-505. https://doi.org/10.1016/j.anbehav.2003.08.028

Zuur AF, Ieno EN (2016) A protocol for conducting and presenting results of regression-type analyses. Methods Ecol Evol 7:636645. https://doi.org/10.1111/2041-210X.12577

Zuur AF, Ieno EN, Walker N et al (2009) Mixed effects models and extensions in ecology with R. Springer Science \& Business Media, New York

Zuur AF, Ieno EN, Elphick CS (2010) A protocol for data exploration to avoid common statistical problems. Methods Ecol Evol 1:3-14. https://doi.org/10.1111/j.2041-210X.2009.00001.x 